This is the author's final, peer-reviewed manuscript as accepted for publication. The publisher-formatted version may be available through the publisher's web site or your institution's library.

\title{
Flow condensation heat transfer enhancement in a mini- channel with hydrophobic and hydrophilic patterns
}

Melanie M. Derby, Abhra Chatterjee, Yoav Peles, Michael K. Jensen

\section{How to cite this manuscript}

If you make reference to this version of the manuscript, use the following information:

Derby, M. M., Chatterjee, A., Peles, Y., \& Jensen, M. K. (2014). Flow condensation heat transfer enhancement in a mini-channel with hydrophobic and hydrophilic patterns. Retrieved from http://krex.ksu.edu

\section{Published Version Information}

Citation: Derby, M. M., Chatterjee, A., Peles, Y., \& Jensen, M. K. (2014). Flow condensation heat transfer enhancement in a mini-channel with hydrophobic and hydrophilic patterns. International Journal of Heat and Mass Transfer, 68, 151-160.

Copyright: @ 2013 Elsevier Ltd.

Digital Object Identifier (DOI): doi:10.1016/j.ijheatmasstransfer.2013.09.024

Publisher's Link: http://www.sciencedirect.com/science/article/pii/S0017931013007989

This item was retrieved from the K-State Research Exchange (K-REx), the institutional repository of Kansas State University. K-REx is available at http://krex.ksu.edu 


\title{
Flow condensation heat transfer enhancement in a mini-channel with hydrophobic and hydrophilic patterns
}

\author{
Melanie M. Derby ${ }^{\text {a,b, }}{ }^{*}$, Abhra Chatterjee ${ }^{a}$, Yoav Peles ${ }^{a}$, Michael K. Jensen ${ }^{\text {a }}$ \\ ${ }^{a}$ Department of Mechanical, Aerospace, and Nuclear Engineering \\ Rensselaer Polytechnic Institute \\ Troy, NY 12180, United States \\ ${ }^{\mathrm{b}}$ Department of Mechanical and Nuclear Engineering \\ Kansas State University \\ Manhattan, KS 66502, United States
}

${ }^{*}$ Corresponding author

Telephone: 17855322606

Fax: 17855327057

Contact E-mail: derbym@ksu.edu 


\begin{abstract}
The study examined the enhancement of flow condensation of steam on hydrophobic and hydrophilic surfaces. Six $1.06 \mathrm{~mm}$ mini-gaps were tested at pressures of $350 \mathrm{kPa}$ to $400 \mathrm{kPa}$, average qualities of 0.2 to 0.95 and mass fluxes of 50 to $200 \mathrm{~kg} / \mathrm{m}^{2} \mathrm{~s}$. The surfaces included hydrophilic copper, hydrophobic Teflon $\mathrm{AF}^{\mathrm{TM}}$, and four surfaces with combined Teflon and hydrophilic patterns; pattern selection was guided by an analytical model. Condensing heat transfer coefficients on hydrophobic and hydrophobic/hydrophilic patterned surfaces reached a value of up to $425,000 \mathrm{~W} / \mathrm{m}^{2} \mathrm{~K}$, surpassing the hydrophilic surface by an order of magnitude. Enhancement factors of 3.2 to 13.4 times that of the hydrophilic channel were found in the hydrophobic channel; combined with a lack of dependence on mass flux or quality, the data strongly suggested that dropwise condensation was promoted and sustained throughout the flow condensation process on hydrophobic and patterned surfaces. For the hydrophilic copper minigap, heat transfer coefficients were a strong function of quality, as well as a function of mass flux at higher qualities, which demonstrated the development and growth of a liquid film as quality decreased, and were well predicted by the Kim et al. (2013) correlation, with a mean average error of $8.9 \%$.
\end{abstract}

Keywords: Condensation, hydrophobic, hydrophilic, pattern, minichannel, microchannel 


\section{Introduction}

Condensers are found in numerous industrial applications, such as power plants and water desalination systems, and more compact and effective condensers would reduce the systems' size and weight while increasing power. In order to create improved condensers, fundamental advancements in condensation are needed. Macro-scale condensation has been well documented after over fifty years of study $[1,2]$. More recently, smaller diameter channels have been shown to offer higher heat transfer coefficients than macro channels, yet mini- and micro-scale condensation has only been explored for the last ten to fifteen years $[3,4]$. Despite larger heat transfer coefficients achieved by researchers at the mini- and micro-scales, few enhancements other than channel shape have been found at the mini- and micro-scale. Dropwise condensation, on external surfaces and in vapor space, offered an order of magnitude enhancement in heat transfer coefficients [5-13] but has seldom been applied to internal flows. However, promotion of dropwise condensation in internal condensation would reduce condenser size.

Condensation in mini- and micro-channels has garnered great interest over the last decade with an emphasis on refrigerants used for electronics cooling and miniaturized vapor compression cycles. Hydraulic diameter, mass flux, quality, and flow regime have been identified as the governing parameters of filmwise condensation. Heat transfer coefficients have been generally found to increase as diameter decreases at the mini- and micro-scales [14-16]. Condensation heat transfer coefficients increased with increasing mass flux and quality $[3,4,17$ 20], with a few exceptions found at lower mass fluxes [14, 21]. Flow regimes affected condensation behavior; the absence of stratified flow, and the presence of annular flow at the mini- and micro-scales suggested that gravity does not play a significant role in small scale condensation [17, 20, 22-25]. 
Although mini- and micro-scale condensation heat transfer coefficients are higher than those found at the macro-scale, efforts to further enhance condensation heat transfer have focused on channel shape. In non-circular channels, condensate gathers in corners due to surface tension, thinning the liquid film in areas away from corners and enhancing the heat transfer coefficient. However, depending on channel length and other variables, length-averaged heat transfer coefficients in a circular tube may be higher or lower than a rectangular channel $[14,26]$. It was expected that shapes with sharp corners would yield heat transfer enhancements [27], yet this has not been observed in all studies [28, 29].

Surface modification, though rarely applied to internal flows, has dramatically enhanced external condensation. Fang et al. [16, 30] studied micro-scale steam condensation in silicon channels coated with self-assembled monolayers, thus creating hydrophobic, hydrophilic, and semi-hydrophobic surfaces. A film wetted the hydrophilic channel walls, while dropwise condensation at the inlet of the hydrophobic channel yielded a slightly (15\%) higher heat flux compared to the hydrophilic tube. In contrast, significant enhancement has been found by promoting dropwise condensation of steam on external tubes and plates, which offered heat flux enhancements of 5 to 20 times that of filmwise condensation under the same conditions [5-13]. Surface modifications promote dropwise condensation by altering contact angles or lowering surface energies, using methods such as coating with polymers [31, 32] and self-assembled monolayers [33, 34], altering surface roughness [8] [11, 35], electroplating [36], and ion implantation [10].

There was an apparent tradeoff in two studies which examined the coexistence of dropwise and filmwise condensation on external surfaces; in one study [37], performance was superior when dropwise condensation existed on top of the tube and filmwise on the bottom, as the disruption of the liquid film by falling droplets enhanced heat transfer. In another study [38], 
the best configuration was when filmwise condensation was on the upper part of the flat plate and dropwise condensation was on the lower part, since film rivulets would clean the dropwise condensation surface. Since the majority of heat transfer occurs through the smallest drops in dropwise condensation [39], droplet sweeping reduces droplet size, thus increasing heat transfer $[40-42]$.

As there have been few studies on internal flow condensation enhancement other than channel shape, the objective of this study is to understand the effects of surface modifications on condensation in a mini-gap. Surface modifications promote dropwise condensation, and the condensation enhancement of hydrophobic surfaces is examined.

\section{Experimental Method and Apparatus}

In order to achieve dropwise condensation in an internal flow, patterned hydrophobic/hydrophilic surfaces were fabricated in a 1.06-mm mini-gap. Six patterns were selected to test on the basis of analytical modeling. Condensation heat transfer coefficients were measured and tested in an open loop steam experimental apparatus.

\subsection{Analytical modeling for pattern selection}

An analytic model guided the selection of hydrophobic/hydrophilic patterns. The geometry was a mini-gap with specified height, $d$, and cooled length, $L_{t o t}$; the channel was cooled on one side and assumed to be adiabatic on the remaining three (Fig. 1). The cooled length contained both hydrophilic and hydrophobic strips. At a specified quality, it was assumed that all liquid gathered on hydrophilic segments with a specified contact angle $\beta$, determined from experiments. The liquid droplet was modeled using a parabola, and the integral of all liquid droplets yielded the total liquid area. Also, the number of hydrophilic strips was specified by the user, and the remaining area was hydrophobic. 
The length of the channel occupied by liquid, and thus filmwise condensation, $L_{F W C}$, was

$E_{\text {Fwe }}=N E_{\text {dropire }}$

for droplets on $N$ hydrophilic areas of length $L_{\text {droplet }}$, while the length occupied by dropwise condensation $L_{P W \mathcal{F}}$ was the difference between the total length and filmwise condensation

length.

The area occupied by liquid was then related to the void fraction according to:

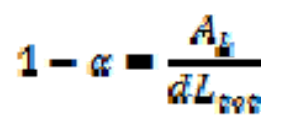

Butterworth [43] determined a simple curve fit based on the work of Lockhart and Martinelli [2] to relate void fraction to quality via the Martinelli parameter $X$,

$a=\frac{1}{1+0,28 X^{0.71}}$

where $X$ was defined for four cases. The flow was assumed to be laminar, such that the pertinent Martinelli parameter $X_{v v}$ for viscous liquid-viscous vapor was defined as

$X_{w}^{2}=\left(\frac{1-x}{x}\right) \frac{\beta_{y}}{\beta_{l} \mu_{l}}$

where the fluid properties (liquid and vapor densities, $\rho_{l}$ and $\rho_{v}$, and liquid and vapor viscosities, $\mu_{l}$ and $\left.\mu_{v}\right)$ were evaluated for steam. The Butterworth [43] equation linked the void fraction, 
obtained through geometry, to quality — a parameter of interest because condensation heat transfer coefficients have been found to be a strong function of quality $[3,28,44]$.

The remaining variables were dropwise and filmwise condensation heat transfer coefficients, $h_{D W C}$ and $h_{F W C}$. Due to the lack of reported dropwise condensation in internal flow, the dropwise condensation heat transfer coefficient was approximated using the work of Baojin et al. [8], who observed dropwise condensation heat transfer coefficients of $60,000 \mathrm{~W} / \mathrm{m}^{2} \mathrm{~K}$ for steam condensation on a vertical, unmodified titanium surface with $80 \%$ dropwise condensation coverage. For the purposes of this model, dropwise condensation heat transfer coefficients on the hydrophobic condensation surface were conservatively estimated to be $40,000 \mathrm{~W} / \mathrm{m}^{2} \mathrm{~K}$. The filmwise heat transfer coefficient was calculated directly from the average film thickness in the hydrophilic areas, and length-averaged heat transfer coefficients were estimated,

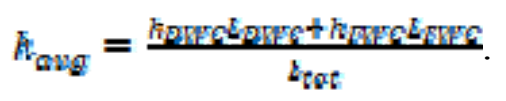

The number of hydrophilic strips, $N$, and quality were supplied as inputs to the model, while the model predicted the length of hydrophilic strip $L_{\text {droplet }}$ and subsequently, the lengthaveraged heat transfer coefficient. The dropwise condensation heat transfer coefficient was approximated from a study of condensation with low flow rates on a vertical, unmodified titanium surface; the area averaged heat transfer coefficient for $80 \%$ dropwise condensation was $60,000 \mathrm{~W} / \mathrm{m}^{2} \mathrm{~K}[8]$, and the hydrophobic dropwise condensation heat transfer coefficients for this model were conservatively estimated to be $40,000 \mathrm{~W} / \mathrm{m}^{2} \mathrm{~K}$.At qualities of 0.95 , the lengthaveraged heat transfer coefficients remained close to the assumed dropwise condensation value. However, as quality decreased, the model showed a significant effect of the number of hydrophilic strips on the average heat transfer coefficient. In Fig. 2, the left hand side represents fewer, larger liquid droplets, and as the number of hydrophilic strips increased, there are more, 
smaller droplets. At lower qualities $(x<0.50)$ more, smaller hydrophilic strips mean that a larger channel length is occupied by liquid in order to fit the same volume of liquid. At low qualities $(x=0.05)$, liquid on only one hydrophilic strip $(N=1)$ spread over a length of $1.6 \mathrm{~mm}(17 \%$ of the channel total), while the four droplets $(N=4)$ combined accounted for $3.1 \mathrm{~mm}(33 \%)$ of the channel. Fewer hydrophilic strips were predicted to be more effective at achieving higher condensation heat transfer coefficients, because the droplets occupied less of the total length, thus exposing more area to the high dropwise condensation heat transfer coefficients.

As a result of this modeling, six surfaces were selected and fabricated: completely hydrophilic $(N \rightarrow \infty)$, completely hydrophobic $(N=0)$, and four patterned surfaces $(N=1,2,3$, and 7).

\subsection{Hydrophobic/hydrophilic surface patterning}

Hydrophilic surfaces promote filmwise condensation, but it was hypothesized that hybrid hydrophobic/hydrophilic surfaces would gather the liquid on the hydrophilic regions, thus promoting dropwise condensation in the hydrophobic regions. Oxygen-free copper surfaces were coated with Teflon $\mathrm{AF}^{\mathrm{TM}}$ and selectively patterned to form hydrophobic and hydrophilic patterned surfaces for condensation. Due to the size of the copper coupon, dip-coating the Teflon was the preferred application method, following a procedure similar to that used for the creation of pool boiling surfaces by Betz et al. [45]. First, selected regions, such as the coupon backside and thermocouple holes, were covered in Kapton tape to prevent Teflon coating. Next, the copper channel was cleaned with isopropyl alcohol and plasma etched. The surfaces were then dipped in a solution of Teflon AF 1601S, 6\% solids dissolved in FC72, diluted (1:24) with solvent FC40. Once coated, the coupons were heated at $165{ }^{\circ} \mathrm{C}$ for 24 hours to evaporate the 
solvent. The process was successful in creating a conformal Teflon coating of thickness $260 \mathrm{~nm}$ $\pm 25 \mathrm{~nm}$, as determined through destructive testing and imaging (Fig. 3). The contact angles of water on untreated hydrophilic copper and hydrophobic Teflon $\mathrm{AF}^{\mathrm{TM}}$ surfaces were measured using an optical goniometer (Fig. 4) and were $40^{\circ}$ and $120^{\circ}$, respectively.

After coating with Teflon, patterns were transferred from a patterned silicon hard mask to the channel via a plasma etch, creating hydrophobic/hydrophilic surfaces. The area under the hard mask remained hydrophobic, while the Teflon coating was selectively removed, exposing the hydrophilic copper surface. Patterned surfaces were created for $N=1,2,3$, and 7 , as well as completely hydrophilic $(N=0)$ and completely hydrophobic $(N \rightarrow \infty)$, Fig. 5 and Fig. 6 . Since the channels were $100 \mathrm{~mm}$ in length, silicon hard masks were fabricated from six-inch $(0.15 \mathrm{~m})$ wafers, and created using a lithography and deep reactive ion etching process. A method was successfully developed to create patterned surface, detailed in Derby [46].

\subsection{Test section design}

The condensation test section (Fig. 7) consisted of two parts: an interchangeable coupon which was joined to a heat flux measuring base; steam flowed through a $0.56 \mathrm{~mm}$ by $9.6 \mathrm{~mm}$ mini-gap channel (hydraulic diameter $1.06 \mathrm{~mm}$ ) machined into the coupon's top surface.; a large surface area was available for patterning. The mini-gap coupon was joined to the base with high thermal conductivity indium and indium-silver $0.05 \mathrm{~mm}$ thick solder ribbon preforms (Indium Corp. of America) and aligned with Teflon alignment pins.

The test section was designed to accurately measure heat flux, wall temperature, quality, and fluid temperature. Unlike boiling experiments, where heater power can be easily obtained, heat flux measurements in condensation are difficult [47]. "Heat flux was measured in three distinct measuring segments (Fig. 8), by five 0.8-mm diameter sheathed thermocouples in each 
segment, installed in 1-mm diameter wholes with a thin layer of thermal grease. The temperature gradient was calculated over a maximum transverse distance of $32 \mathrm{~mm}$, and Fourier's law was utilized to measure heat flux [28, 48].Wall temperatures were measured directly via three thermocouples installed in the coupon itself. For single-phase flow, fluid temperatures were determined indirectly through a series of energy balances on the test section; in the same manner, quality was determined from a series of energy balances for two-phase flow. For two-phase flows, the inlet pressure and pressure drop across the test section were measured; pressure was determined at the center of each measuring segment using a linear pressure drop model, and the fluid temperature was calculated to be the saturation temperature for that pressure.

Steam entered and exited the mini-gap through a stainless steel cover plate at an angle of $35^{\circ}$ from horizontal, to lessen heat transfer enhancement from impingement. An o-ring seal joined the cover plate and coupon; additionally, the mating copper surface was coated with Teflon to prevent galvanic corrosion. Cooling was provided at the heat flux measuring base by an aluminum plate heat exchanger, and thermal grease was applied the interface. The entire test section assembly was compressed by six bolts in order to seal and promote good thermal contact between parts.

\subsection{Apparatus}

An open loop (Fig. 9) allowed for a wide range of test section qualities and mass fluxes. Steam at $440 \mathrm{kPa}$ was filtered by seven $40-\mu \mathrm{m}$ parallel filters, and then passed through a separation tank to ensure near-saturated steam. Exiting high quality steam was then superheated $30-50{ }^{\circ} \mathrm{C}$, ensuring that enthalpy before the pre-condenser could be accurately calculated through temperature and pressure measurements (Omega PX303-300A5V) after the pre-heater. A short 
or long tube-in-tube counterflow pre-condenser was used, cooled via open loop city water, to set a wide variety of different test section inlet qualities; the pre-condenser outlet quality was calculated through a cooling water energy balance using measured water mass flow rates and temperature differences. To obtain the highest test section inlet qualities, the loop was used without a pre-condenser. A 4-kW heater was installed on the cooling water side to vary the cooling water inlet temperature from $10{ }^{\circ} \mathrm{C}$ to $50{ }^{\circ} \mathrm{C}$ to further adjust pre-condenser outlet/test section inlet quality. Cooling water mass flow rate and pressure (above atmospheric) were controlled to suppress undesirable sub-cooled boiling on the cooling water side.

Steam entered the test section with a known quality. Temperature and absolute pressure (Omega PX303-100A5V) were measured at the test section inlet (needed for calculating enthalpy for single-phase validation cases) and was used to check saturation temperature and pressure for two-phase cases. Exit pressure was obtained from a differential pressure transducer (Setra model 230), and the pressure drop set the fluid temperature inside the test section. Since small quality changes were set across the test section, a tube-in-tube, city water cooled post-condenser condensed the remaining steam fully, enabling the condensate mass flow rate to be measured downstream of the test section with a weigh tank and stopwatch. Additionally, a valve after the post-condenser and before the rotameter regulated the flow and suppressed flow instabilities, and the rotameter permitted the visualization of steady flow rates.

\subsection{Experimental Procedures}

Tests were run at steady state conditions. First, cooling water flow rates were set in the test section, post-condenser, and pre-condenser (if applicable). Once steady cooling water temperatures and flow rates were obtained, steam entered the system at a desired flow rate, and the two pre-heaters were switched on, superheating the steam $30-50^{\circ} \mathrm{C}$ above the supplied steam saturation temperature $\left(142^{\circ} \mathrm{C}-144^{\circ} \mathrm{C}\right)$. Data were recorded thirty to forty minutes after cooling 
water and steam flow rates were set and after the temperatures were steady for at least ten minutes. Temperature and voltage data were recorded via LabVIEW for three to five minutes and later averaged, while cooling water and steam condensate mass flow rates were measured with weigh tanks and stopwatches.

\subsection{Data Reduction}

For single-phase and two-phase flows, segment-averaged heat transfer coefficients were found using the expression

$$
h_{i}=\frac{q_{i}^{\prime \prime}}{\left(q_{f i}-T_{w_{i}}\right)}
$$

Wall temperatures were measured in the coupon by thermocouples installed $1 \mathrm{~mm}$ below the channel. The heat transfer rate in each column was calculated assuming one-dimensional conduction (confirmed through numerical modeling of the copper block),

$$
\phi_{t}=-k W L_{s e g i t} \frac{d T}{d y_{t}}
$$

where $k$ was the conductivity of oxygen-free copper, $W$ was the width of the block, $L_{s e g, i}$ was the length of the column segment, and $d T / d y_{i}$ was the temperature gradient in each measuring segment, with $i=1$ for the inlet segment, $i=2$ for the middle segment, and $i=3$ for the exit segment. The channel heat flux was

$$
q_{t}^{\prime \prime}=\frac{Q_{t}}{A_{o h, t}}
$$

where $A_{o b_{b} t}$ was the three-sided heat transfer surface area of the channel. 
For single phase validation, the test section energy balance obtained using the copper heat flux sensors and the temperature gradient to calculate heat flux,

where $\phi_{\sigma}$ was the total heat transfer rate from the copper block through the gradient measurement

method, including segment-averaged heat transfer rates $\phi_{1}, \phi_{2}$ and $\phi_{3}$; the first and third segment included the additional inlet and exit header areas, respectively. In single-phase validation, the total heat transfer rate from the copper block was compared to the enthalpy change of the cooled liquid water.

\subsection{Uncertainties}

A propagation of uncertainty analysis was conducted to estimate the uncertainty in condensation heat transfer coefficients [49], qualities, and other quantities.

The average quality across each measuring segment was obtained through a series of energy balances. Beginning with the pre-condenser, the steam cooling rate was determined from the cooling water energy balance, incorporating heat losses; validation experiments showed that the measured cooling water heat transfer rate underpredicted the steam-side heat transfer rate by an average of $2.9 \%$. Cooling water and steam mass flow rates were obtained using a weigh tank and stopwatch, so the uncertainty in both mass flow rates depended on measured mass, $m$, and

time, $t$, and was incorporated into the uncertainty analysis; the uncertainty in mass measurement

was assumed to be $\pm 1 \mathrm{~g}$, larger than the accuracy of the scale (Citizen CT-8000H), and the uncertainty in time measurements was assumed to be $\pm 1 \mathrm{~s}$. Uncertainties in subsequent energy 
balances were calculated, yet uncertainties in average test section qualities were low, of the range \pm 0.01 to 0.03 .

Uncertainties in condensation heat transfer coefficients were found using a propagation of uncertainty analysis [49] and are detailed in Derby [46]. The uncertainty of the thermal conductivity, wall temperature, and thermocouple location were $\pm 8 \mathrm{~W} / \mathrm{mK}, \pm 0.2{ }^{\circ} \mathrm{C}$, and \pm 0.13 $\mathrm{mm}$, respectively. Fluid saturation temperature was determined by accurately measuring saturation pressure; an absolute pressure transducer at the test section inlet (range 0 to $690 \mathrm{kPa}$, uncertainty $\pm 1.725 \mathrm{kPa}$ ) measured inlet pressure, combined with a differential pressure transducer (range of 0 to $69 \mathrm{kPa}$, uncertainty $\pm 0.172 \mathrm{kPa}$ ) resulted in two-phase fluid temperatures with uncertainties of $\pm 0.2^{\circ} \mathrm{C}$. All pressure transducers were calibrated with a deadweight tester and mounted on pigtails. The uncertainties from measured areas were negligible. The uncertainty of the temperature gradient was obtained with the method of Kedzierski and Worthington [48],

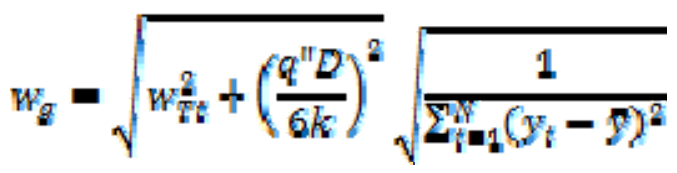

where $w_{T i}$ was the temperature sensor uncertainty of $\pm 0.2^{\circ} \mathrm{C}, y_{i}$ was the position of the $i$ th thermocouple, and $\bar{y}$ was the average position of the thermocouples. For single-phase cases, the heat flux uncertainty was dominant. For two-phase flow, especially the Teflon coated surfaces, low fluid-wall temperature differences were the largest contributor to condensation heat transfer coefficient uncertainty. Temperature measurements were critical for accurate condensation heat transfer and quality measurement. For this reason, all type $\mathrm{T}$ thermocouple probes were calibrated carefully using a LabVIEW calibration wizard over a wide range of temperatures, 
including ice point, $10{ }^{\circ} \mathrm{C}$ to $80{ }^{\circ} \mathrm{C}$ in increments of $5{ }^{\circ} \mathrm{C}$, and boiling point. Measured temperatures were compared to a reference thermometer with an accuracy of $\pm 0.05{ }^{\circ} \mathrm{C}$.

\section{Results and Discussion}

\subsection{Single-phase validation}

Single-phase experiments, conducted to validate the experimental apparatus for subsequent condensation results, compared test section energy balances from the gradient method to overall fluid energy balances, and evaluated Nusselt numbers for known, laminar flow conditions.

Subcooled liquid entered the test section and was further cooled. The decrease in sensible heat on the fluid side was compared to the total heat transfer rate measured through using Fourier's Law. Good agreement, with differences of less than $10 \%$, was found between the two energy balances (Fig. 10), yielding confidence in the test section heat flux measurement method.

Because the length of the first measuring segment was $33 \mathrm{~mm}$, values in the second measuring segment were fully developed. The reported data were for the second measuring segment, as exit and entrance effects, from impinging flow due to the angled inlet and exit, affected the heat transfer coefficients in the first and third measuring segments (but not the energy balances).

Laminar Nusselt numbers were measured with respect to Reynolds number and were compared to laminar flow between parallel plates, as the mini-gap offered a high aspect ratio (width/height=17 (Fig. 11). Additionally, the cover plate was not actively cooled and well insulated from the environment, similar to the case of parallel plates with one side insulated $(N u=4.86[50])$. Excellent agreement was achieved between the measured and predicted Nusselt numbers for laminar flow. Combined with the good agreement in overall energy balance, these 
single-phase validation tests demonstrated that heat transfer coefficients could be accurately measured for condensation heat transfer.

\subsection{Condensation data}

Condensation studies examined the effects of mass flux, quality, and surface characteristics on flow condensation heat transfer behavior in a single channel, without flow instabilities associated with parallel channels. Condensation heat transfer coefficient data were reported from the second measuring segment, which, unlike the first and third measuring segments, was not affected by inlet and exit effects.

\subsubsection{Hydrophilic copper mini-gap}

Condensation heat transfer coefficients were observed to be a strong function of quality and lesser function of mass flux in the hydrophilic mini-gap, commensurate with the findings in the literature $[3,4,17,27,51]$. Condensation heat transfer coefficients were measured with uncertainties ranging from $\pm 5 \%$ to $\pm 29 \%$, over a mass flux range of 50 to $200 \mathrm{~kg} / \mathrm{m}^{2} \mathrm{~s}$ and a wide range of qualities. Measuring segment quality changes were typically less than $5 \%$, except at the lowest mass flux of $50 \mathrm{~kg} / \mathrm{m}^{2} \mathrm{~s}$ when quality changes of $12 \%$ were observed; uncertainties in average quality were very low, typically \pm 0.01 to \pm 0.03 .

Higher heat transfer coefficients were observed at high qualities in the copper mini-gap (Fig. 12); less liquid at high qualities yielded a thinner liquid film, and consequently higher heat transfer coefficients, which varied by as much as a factor of three based on quality alone. Additionally, there was also an observable increase in heat transfer coefficients with respect to mass flux at higher qualities, especially apparent at mass fluxes of 100 and $150 \mathrm{~kg} / \mathrm{m}^{2} \mathrm{~s}$, for 
which the tested range of quality was largest. A dependence on mass flux was expected and observed, since the heat transfer coefficient typically scales with increasing velocity. Zhang et al. [19] studied laminar steam condensation between parallel plates (gaps spacing $=3 \mathrm{~mm}$ ) using FLUENT, and observed shear thinning of the liquid film at higher vapor velocities. The mass flux dependence observed in the copper mini-gap agreed with the findings in the literature [3, 4, 17, 18], demonstrating that higher shear forces found at higher mass fluxes served to thin the liquid film, thus increasing the heat transfer coefficient.

\subsubsection{Comparison with Correlations}

Condensation data from the copper mini-gap was compared to correlations by Shah [52] and Kim et al. [53] (Fig. 13). The Shah [52] correlation utilized a database containing 22 working fluids, pipe diameters ranging from $2 \mathrm{~mm}$ to $49 \mathrm{~mm}$, mass fluxes of 4 to $820 \mathrm{~kg} / \mathrm{m}^{2} \mathrm{~s}$, and was based on the author's previous boiling correlation. Mean average error was used to assess correlations, where MAE was defined as

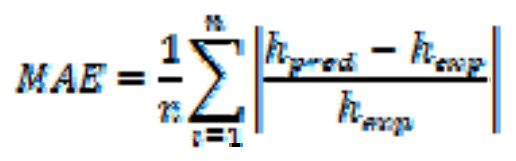

where $h_{\text {pred }}$ was the heat transfer coefficient predicted by the correlation, $h_{\exp }$ was the experimentally determined heat transfer coefficient, and $n$ was the number of data points in a given set. This macro-scale correlation under-predicted the mini-gap data, with a mean average error (MAE) of 27.8\% Kim et al. [53] developed a two-phase multiplier correlation for miniand micro-scale condensation, including seventeen working fluids, hydraulic diameters of 0.424$\mathrm{mm}$ to $6.22-\mathrm{mm}$, and mass fluxes of 53 to $1403 \mathrm{~kg} / \mathrm{m}^{2} \mathrm{~s}$. The correlation utilized the modified Weber number criteria, developed by Soliman [54], to determine whether the flow was annular or slug-bubbly; the majority of the present data were within the annular flow regime, and just 
one out of 26 data points were in the slug-bubbly flow regime. There was excellent agreement between the measured data and predicted values from the Kim et al. [53] correlation, with a MAE of $8.9 \%$ and without a significant bias, despite the absence of steam from the data set used to develop the correlation. Comparisons with the Shah [52] and Kim et al. [53] correlations demonstrated that the measured condensation heat transfer values were reasonable, and, based on the resulted obtained in this study, the Kim et al. [53] correlation is recommended for future predictions of steam in mini-channels

\subsubsection{Comparison with Teflon-coated surface}

Condensation behavior on a Teflon-coated surface differed from the plain copper surface in several notable ways: the heat transfer coefficients were substantially higher, generally in the 300,000 to $400,000 \mathrm{~W} / \mathrm{m}^{2} \mathrm{~K}$ range, and there was no discernible dependence on mass flux or quality (Fig. 14). While heat transfer in the copper mini-gap was very sensitive to quality, theTeflon mini-gap appeared insensitive to quality, which suggested that the condensing liquid was forming droplets as in dropwise condensation, instead of a liquid film that would act as a barrier to condensation; combined with the order of magnitude increase in heat transfer coefficient as compared to the hydrophilic copper mini-gap, the data strongly suggested that dropwise condensation occurred on the Teflon-coated surface. It should be noted that there was a clear difference between the performance of the copper and Teflon mini-gaps, although firm conclusions about the effects of quality on the Teflon surface were difficult to draw due to the uncertainties in heat transfer coefficients; higher condensation heat transfer coefficient uncertainties were a consequence of low fluid-wall temperature differences $\left(<1.0{ }^{\circ} \mathrm{C}\right)$.

\subsubsection{Comparison with hydrophobic/hydrophilic patterned surfaces}


Condensation heat transfer coefficients were measured for a range of mass fluxes and qualities in each of the hydrophobic/hydrophilic patterns and compared to condensation results for the hydrophilic copper and hydrophobic Teflon-coated surfaces (Fig. 15). Heat transfer coefficients from the Teflon and all patterned mini-gaps exceeded those found in the copper mini-gap and did not exhibit a strong dependence on quality, unlike the dependence observed with the plain copper surface. The uncertainties for these condensation heat transfer measurements were high as a result of low fluid-wall temperature differences, so differences in heat transfer coefficients between patterned surfaces were on the order of the uncertainties.

With some reservations due to the uncertainties, it appeared that the patterns with the lowest $(N=1)$ and highest $(N=7)$ number of hydrophilic areas yielded the best heat transfer performance. Three of the patterns $(N=2,3,7)$ had comparable percent hydrophilic area coverage (Table 1), and, yet, the results indicated, but did not conclude, that the performance of the $N=7$ surface was superior. All of these patterns had hydrophilic areas in the corners of the mini-gap, but different widths: $1.10 \mathrm{~mm}$ for $N=2,0.91 \mathrm{~mm}$ for $N=3$, and $0.43 \mathrm{~mm}$ for $N=7$. One hypothesis on this difference in condensation heat transfer coefficient behavior is that the surfaces with the larger hydrophilic areas in the corners $(N=2,3)$ formed growing liquid films in the corners due to surface tension, covering some Teflon coated areas and reducing overall heat transfer rates. Another difference between the surfaces was the lack of branched "on-ramps" in the $N=7$ case (Fig. 6), which could have influenced the condensation heat transfer physics. The results indicated, however, that the condensation phenomenon is not merely a function of hydrophilic area coverage, and there were other factors influencing the condensation process.

To facilitate and quantify the heat transfer enhancement of the patterned and Teflon surfaces, the Teflon and patterned mini-gap data were compared to the copper mini-gap baseline data (Fig. 16). However, since it was shown that quality was the strongest variable governing 
condensation for the copper mini-gap, the data were normalized to account for this effect. Simple equations were curve fit to relate heat transfer coefficients and average qualities for each mass flux in the copper mini-gap. For each surface, every data point was compared to the predicted value of the copper surface from the appropriate curve fit, yielding an enhancement factor of $h_{\text {measured }} / h_{\text {predicted,Cu }}$ (Fig. 16). As expected, the copper enhancement factors ranged from 0.95 to 1.02, and centered around 1 , which indicated the goodness of the predicted baseline values from the curve fits. The Teflon and patterned surfaces enhanced condensation heat transfer for all cases, and the results indicated that performance improved at decreasing quality; at qualities above 0.5 , typical heat transfer enhancements ranged from 3 to 6 . Previous modeling (section 3 ) suggested that the maximum heat transfer enhancement would be found at lower qualities, and experimentally, enhancements of 4 to 13 were seen at qualities below 0.5 . The large condensation heat transfer coefficients observed with the Teflon and patterned mini-gaps further supported the hypothesis that dropwise condensation occurred on these surfaces, mirroring the enhancements found in the literature that dropwise condensation offered enhancements of 5 to 20 that of filmwise condensation [5-13].

In contrast to gravity driven external flows, this study examined the effects of hydrophobic and hydrophilic patterns in internal flow where shear forces mattered. Pattern performance would have been superior to that of a fully Teflon coated surface if thick, liquid films accumulated on the entire Teflon surface, but those liquid films could gather on the hydrophilic areas in the hydrophobic/hydrophilic surfaces. Droplet sweeping via shear forces may be affecting the condensation process, hindering liquid film development on the Teflon coated surface. An analytical [40] and experimental study [41] demonstrated the benefit of droplet sweeping in condensation. The presence of droplets, and the absence of a constant liquid film on the condensing surface, is required in order for droplet sweeping to be an important 
condensing mechanism. Droplet formation, and thus droplet formation, would play a more significant role at higher void fractions were the liquid volume was small relative to the vapor volume, as liquid would not flood or fill the channel. Consequently, void fraction was estimated for the quality range tested using the homogeneous equilibrium model [5] and Lockhart Martinelli model [2]. The formulation of the homogeneous equilibrium model assumed equal liquid and vapor velocities in order to determine the void fraction. Alternatively, using an approach developed by Lockhart and Martinelli [2], Butterworth [43] developed a simple correlation for void fraction, Equation 3, which did not assume equal liquid and vapor velocities, where the Lockhart Martinelli parameter, $X$, was selected for viscous liquid-viscous gas and viscous liquid-turbulent gas flows at mass fluxes of 50 and $200 \mathrm{~kg} / \mathrm{m}^{2} \mathrm{~s}$, respectively.

Using these models, void fraction was estimated for the lowest and highest mass fluxes tested (Fig. 17). Since the density of liquid water is three orders of magnitude higher than that of water vapor, void fraction remained high even as quality decreased for all mass fluxes. For all cases, void fraction was above 0.8 for qualities above 0.1 , and declined rapidly as quality approached zero. Condensation heat transfer coefficients were measured experimentally from qualities nearing 1 to qualities of around 0.15 , and the heat transfer coefficients on Teflon/patterned surfaces did not vary with quality. Over this quality range, the void fraction was high, signifying that the majority of the channel cross sectional area was occupied by vapor, not liquid, and thus it was reasonable to assume that droplet sweeping was occurring.

\section{Conclusions}

Flow condensation of steam was studied inside a mini-gap, including the effects of hydrophobicity on promoting dropwise condensation; a hydrophilic copper 1.06-diameter mini- 
gap was compared to a hydrophobic Teflon coated mini-gap and patterned

hydrophobic/hydrophilic mini-gaps were explored over a range of mass fluxes and qualities.

Condensation heat transfer coefficients were measured accurately in a hydrophilic copper mini-gap, $9.6 \mathrm{~mm}$ by $0.56 \mathrm{~mm}$, with uncertainties between $5 \%$ and $15 \%$ at qualities below 0.5 , and around $15-25 \%$ at higher qualities. It was found that the condensing heat transfer coefficient was a strong function of quality, which signified that a liquid film developed on the condensing surface as vapor was condensed. The heat transfer coefficient was a lesser function of mass flux, especially at high qualities, which denoted the effects of shear forces to thin the liquid film. The micro- and mini-scale Kim et al. [53] correlation predicted the data very well, with a mean average error of $8.9 \%$.

Dropwise condensation of steam was promoted on hydrophobic Teflon $\mathrm{AF}^{\mathrm{TM}}$ coated copper surfaces. Extremely high condensation heat transfer coefficients were observed, ranging from 280,000 to $425,000 \mathrm{~W} / \mathrm{m}^{2} \mathrm{~K}$; higher uncertainties in these measurements were a result of low wall-fluid temperature differences $\left(<1^{\circ} \mathrm{C}\right)$. There was no discernible dependence on quality or mass flux, which suggested that a liquid film was not developing on the Teflon surface, since condensation heat transfer coefficients remained high even at qualities below 0.5. Heat transfer enhancements of 3.2 to 13.4 times that of the copper mini-gap were commensurate with the behavior of dropwise condensation.

Patterned geometries were selected for testing using a simple analytical model, with a range of hydrophilic strips $(N=1,2,3,7)$. The data suggested, but did not conclude, that the best pattern performance was exhibited by two patterns with $N=1$ and 7 , yet the patterned surfaces did not perform as well as the Teflon coated surface. It was posited that the shear forces that led to droplet sweeping and removal were more significant than liquid film development at these tested 
mass fluxes. The Teflon coated mini-gap offered the most condensation heat transfer enhancement.

Several areas of future study emerged from this work. First, further understandings of the flow condensation mechanisms are needed, especially relating to the formation of droplets on a hydrophobic surface in shear driven flow. It was hypothesized that the effects of droplet sweeping from shear forces were the dominant means of heat transfer enhancement in any Teflon coated surface. This hypothesis should be analyzed further, analytically and experimentally, and the flow visualized at lower mass fluxes, where the effects of shear lessen and those of surface tension increase. In addition, future experiments could reduce condensing heat transfer coefficient uncertainties.

\section{Acknowledgments}

The authors acknowledge the financial support of Office of Naval Research through a MURI grant, Grant No. N00014-07-1-0723 entitled "System-Level Approach for Multi-Phase, Nanotechnology-Enhanced Cooling of High-Power Microelectronic Systems," and a graduate

fellowship from the NSF GK12 program, "Building Bridges from High School to Grad School Through Discovery-Based Activities in Energy and the Environment." 


\section{Nomenclature}

\begin{tabular}{|c|c|}
\hline$A$ & Area $\left[\mathrm{m}^{2}\right]$ \\
\hline$d$ & Gap depth, $[\mathrm{m}]$ \\
\hline$D$ & Diameter, $[\mathrm{m}]$ \\
\hline G & Mass flux, $\left[\mathrm{kg} / \mathrm{m}^{2} \mathrm{~s}\right]$ \\
\hline$h$ & Heat transfer coefficient, $\left[\mathrm{W} / \mathrm{m}^{2} \mathrm{~K}\right]$ \\
\hline$k$ & Thermal conductivity $[\mathrm{W} / \mathrm{mK}]$ \\
\hline$L$ & Length, $[\mathrm{m}]$ \\
\hline$\dot{m}$ & Mass flow rate, $[\mathrm{kg} / \mathrm{s}]$ \\
\hline$M A E$ & Mean average error \\
\hline$n$ & Number of samples \\
\hline$N$ & Number of hydrophilic areas in patterned surfaces \\
\hline$q^{\prime \prime}$ & Heat flux, $\left[\mathrm{W} / \mathrm{m}^{2}\right]$ \\
\hline$\dot{q}$ & Heat transfer rate, $[\mathrm{W}]$ \\
\hline$t$ & Time, $[\mathrm{s}]$ \\
\hline$T$ & Temperature, $\left[{ }^{\circ} \mathrm{C}\right]$ \\
\hline$w$ & Uncertainty \\
\hline$W$ & Width, [m] \\
\hline
\end{tabular}




$\begin{array}{ll}x & \text { Quality } \\ X & \text { Lockhart Martinelli parameter } \\ y & \text { Transverse coordinate, }[\mathrm{m}] \\ \alpha & \text { Void fraction } \\ \beta & \text { Contact angle } \\ \mu & \text { Viscosity, }[\mathrm{kg} / \mathrm{ms}] \\ \rho & \text { Density, }\left[\mathrm{kg} / \mathrm{m}^{3}\right]\end{array}$

Subscripts

$\begin{array}{ll}1,2,3 & \text { Corresponding to first, second, third measuring segment } \\ c h & \text { Channel } \\ D W C & \text { Dropwise condensation } \\ \exp & \text { Experimental } \\ f & \text { Fluid } \\ F W C & \text { Filmwise condensation } \\ g & \text { Gradient } \\ i & \text { Index } \\ l & \text { Liquid } \\ L M & \text { Lockhart Martinelli } \\ \text { pred } & \text { Predicted } \\ \text { seg } & \text { Segment } \\ \text { tot } & \text { Total } \\ v & \text { Vapor } \\ v v & \text { Viscous liquid and vapor } \\ v t & \text { Viscous liquid and turbulent vapor } \\ w & \text { Wall }\end{array}$




\section{References}

[1] W.W. Akers, H.A. Deans, O.K. Crosser, Condensing heat transfer within horizontal tubes, Chemical Engineering Progress Symposium Series, 55(29) (1959) 171-176.

[2] R.W. Lockhart, Martinelli, R.C., Proposed correlation of data for isothermal two-phase, twocomponent flow in pipes, Chemical Engineering Progress 45(1) (1949) 39-48.

[3] T.M. Bandhauer, A. Agarwal, S. Garimella, Measurement and modeling of condensation heat transfer coefficients in circular microchannels, Journal of Heat Transfer, 128(10) (2006) 10501059.

[4] R.L. Webb, K. Ermis, Effect of hydraulic diameter on condensation of R-134a in flat, extruded aluminum tubes, Enhanced Heat Transfer, 8 (2001) 77-90.

[5] V.P. Carey, Liquid-Vapor Phase-Change Phenomena, second ed., Taylor \& Francis, New York, NY, 2008.

[6] K. Stephan, Heat Transfer in Condensation and Boiling, English ed., Spinger-Verlag, Berlin, Germany, 1992.

[7] A.J. Ede, An Introduction to Heat Transfer Principles and Calculations, first ed., Pergamon Press, Oxford, England, 1967.

[8] Q. Baojin, Z. Li, X. Hong, S. Yan, Experimental study on condensation heat transfer of steam on vertical titanium plates with different surface energies, Experimental Thermal and Fluid Science, 35(1) (2011) 211-218.

[9] R.W. Bonner III, Dropwise condensation life testing of self assembled monolayers, in: Proceedings of the 14th International Heat Transfer Conference, Washington, DC, 2010, pp. $221-226$. 
[10] Z. Dongchang, L. Zaiqi, L. Jifang, New surface materials for dropwise condensation, in: Proceedings of the 8th International Heat Transfer Conference, San Francisco, CA, 1986, pp. 1677-1682.

[11] X. Ma, S. Wang, Z. Lan, A. Wang, B. Peng, Dropwise condensation heat transfer on superhydrophobic surface in the presence of non-condensable gas, in: Proceedings of the 14th International Heat Transfer Conference, Washington, DC, 2010, pp. 71-79.

[12] P.J. Marto, D.J. Looney, J.W. Rose, A.S. Wanniarachchi, Evaluation of organic coatings for the promotion of dropwise condensation of steam, International Journal of Heat and Mass Transfer, 29(8) (1986) 1109-1117.

[13] J. Plawsky, M. Ojha, A. Chatterjee, P. Wayner, Review of the effects of surface topography, surface chemistry, and fluid physics on evaporation at the contact line, Chemical Engineering Communications, 196(5) (2009) 658-696.

[14] J.S. Shin, M.H. Kim, An experimental study of flow condensation heat transfer inside circular and rectangular mini-channels, Heat Transfer Engineering, 26(3) (2005) 36-44.

[15] A. Agarwal, S. Garimella, Representative results for condensation measurements at hydraulic diameters 100Microns, Journal of Heat Transfer, 132(4) (2010) 041010.

[16] C. Fang, M. David, F.-m. Wang, K.E. Goodson, Influence of film thickness and crosssectional geometry on hydrophilic microchannel condensation, International Journal of Multiphase Flow, 36(8) (2010) 608-619.

[17] W.-W.W. Wang, T.D. Radcliff, R.N. Christensen, A condensation heat transfer correlation for millimeter-scale tubing with flow regime transition, Experimental Thermal and Fluid Science, 26 (2002) 473-485.

[18] S. Chowdhury, E. Al-Hajri, S. Dessiatoun, A. Shooshtari, M. Ohadi, An experimental study of condensation heat transfer and pressure drop in a single high aspect ratio micro-channel for 
refrigerant R134a, in: Fourth International Conference on Nanochannels, Microchannels, and Minichannels, Limerick, Ireland, 2006, pp. 147-154.

[19] Y. Zhang, A. Faghri, M.B. Shafii, Capillary blocking in forced convective condensation in horizontal miniature channels, Journal of Heat Transfer, 123(3) (2001) 501.

[20] J.W. Coleman, S. Garimella, Two-phase flow regimes in round, square and rectangular tubes during condensation of refrigerant R134a, International Journal of Refrigeration, 26(117128) (2003).

[21] M. Matkovic, A. Cavallini, D. Del Col, L. Rossetto, Experimental study on condensation heat transfer inside a single circular minichannel, International Journal of Heat and Mass Transfer, 52(9-10) (2009) 2311-2323.

[22] S. Garimella, Condensation flow mechanisms in microchannels: Basis for pressure drop and heat transfer models, Heat Transfer Engineering, 25(3) (2004) 104-116.

[23] A. Cavallini, Condensation à l'extérieur et à l'intérieur de tubes lisses et à surface augmentée — point sur le recherche récente, International Journal of Refrigeration, 26(4) (2003) 373-392. [24] Y. Chen, M. Shi, P. Cheng, G.P. Peterson, Condensation in microchannels, Nanoscale and Microscale Thermophysical Engineering, 12(2) (2008) 117-143.

[25] P. Cheng, G. Wang, X. Quan, Recent work on boiling and condensation in microchannels, Journal of Heat Transfer, 131(4) (2009) 043211.

[26] H.S. Wang, J.W. Rose, A theory of film condensation in horizontal noncircular section microchannels, Journal of Heat Transfer, 127(10) (2005) 1096.

[27] A. Agarwal, T.M. Bandhauer, S. Garimella, Heat transfer model for condensation in noncircular microchannels, in: Proceedings of the Fifth International Conference on Nanochannels, Microchannels and Minichannels, Puebla, Mexico, 2007, pp. 117-126. 
[28] M.M. Derby, Condensation heat transfer in square, triangular, and semi-circular minichannels, Rensselaer Polytechnic Institute, Troy, NY, 2010.

[29] M.M. Derby, H.J. Lee, Y. Peles, M.K. Jensen, Condensation heat transfer in square, triangular, and semi-circular mini-channels, International Journal of Heat and Mass Transfer, 55(1-3) (2012) 187-197.

[30] C. Fang, J.E. Steinbrenner, F.-M. Wang, K.E. Goodson, Impact of wall hydrophobicity on condensation flow and heat transfer in silicon microchannels, Journal of Micromechanics and Microengineering, 20(4) (2010) 045018.

[31] K.M. Holden, A.S. Wanniarachchi, P.J. Marto, D.H. Boone, J.W. Rose, The use of organic coatings to promote dropwise condensation of steam, Journal of Heat Transfer, 109 (1987) 768774.

[32] T. Haraguchi, R. Shimada, S. Kumagai, T. Takeyama, The effect of polyvinylidene chloride coating thickness on promotion of dropwise steam condensation, International Journal of Heat and Mass Transfer, 34(12) (1991) 3047-3054.

[33] A.K. Das, H.P. Kilty, P.J. Marto, G.B. Andeen, A. Kumar, The use of an organic selfassembled monolayer coating to promote dropwise condensation of steam on horizontal tubes, Journal of Heat Transfer, 122 (2000) 278-286.

[34] S. Vemuri, K. Kim, An experimental and theoretical study on the concept of dropwise condensation, International Journal of Heat and Mass Transfer, 49(3-4) (2006) 649-657.

[35] A.D. Sommers, A.M. Jacobi, Creating micro-scale surface topology to achieve anisotropic wettability on an aluminum surface, Journal of Micromechanics and Microengineering, 16(8) (2006) 1571-1578.

[36] L. Cheng, T. Chen, Heat transfer and flow friction characteristics of a compact plate-type condenser, Proceedings of the ASME Heat Transfer Division, 361-3 (1998) 489-496. 
[37] X.-h. Ma, Condensation Heat Transfer of Steam on Vertical Dropwise and Filmwise Coexisting Surfaces with a Thick Organic Film Promoting Dropwise Mode, Experimental Heat Transfer, 16(4) (2003) 239-253.

[38] S. Kumagai, S. Tanaka, H. Katsuda, R. Shimada, On the enhancement of filmwise condensation heat transfer by means of the coexistence with dropwise condensation sections, Experimental Heat Transfer, 4(1) (1991) 71-82.

[39] J.W. Rose, Dropwise condensation theory, International Journal of Heat and Mass Transfer, 24 (1981) 191-194.

[40] C. Yamali, H. Merte Jr., A theory of dropwise condensation at large subcooling including the effect of the sweeping, Heat and Mass Transfer, 38 (2002) 191-202.

[41] M.H.M. Grooten, C.W.M. van der Geld, Dropwise condensation from flowing air-steam mixtures: Diffusion resistance assessed by controlled drainage, International Journal of Heat and Mass Transfer, 54(21-22) (2011) 4507-4517.

[42] B.S. Sikarwar, N.K. Battoo, S. Khandekar, K. Muralidhar, Dropwise condensation underneath chemically textured surfaces: Simulation and experiments, Journal of Heat Transfer, 133(2) (2011) 021501.

[43] D. Butterworth, A comparison of some void-fraction relationships for co-current gas-liquid flow, Int. J. Multiphase Flow, 1 (1975) 845-850.

[44] H. Wang, J. Rose, H. Honda, A theoretical model of film condensation in square section horizontal microchannels, Chemical Engineering Research and Design, 82(4) (2004) 430-434. [45] A.R. Betz, J. Xu, H. Qiu, D. Attinger, Do surfaces with mixed hydrophilic and hydrophobic areas enhance pool boiling?, Applied Physics Letters, 97(14) (2010) 141909.

[46] M.M. Derby, Study of flow condensation enhancement with hydrophobic and hydrophilic patterns, Rensselaer Polytechnic Institute, Troy, NY, 2013. 
[47] M.M. Derby, H.J. Lee, R.C. Craft, G.J. Michna, Y. Peles, M.K. Jensen, Exploration of experimental techniques to determine the condensation heat flux in microchannels and minichannels, in: Proceedings of the 14th International Heat Transfer Conference, Washington, D.C., 2010, pp. 169-176.

[48] M.A. Kedzierski, J.L. Worthington III, Design and machining of copper specimens with micro holes for accuarate heat transfer measurements, Experimental Heat Transfer, 6 (1993) 329344.

[49] R.J. Moffat, Describing the uncertainties in experimental results, Experimental Thermal and Fluid Science, 1 (1998) 3-17.

[50] A. Bejan, Convection Heat Transfer, third ed., John Wiley \& Sons, Hoboken, NJ, 2004.

[51] X. Ma, X. Fan, Z. Lan, T. Hao, Flow patterns and transition characteristics for steam condensation in silicon microchannels, Journal of Micromechanics and Microengineering, 21(7) (2011) 075009.

[52] M.M. Shah, An Improved and extended general correlation for heat transfer during condensation in plain tubes, HVAC\&R Research, 15(5) (2009) 889-913.

[53] S.-M. Kim, I. Mudawar, Universal approach to predicting heat transfer coefficient for condensing mini/micro-channel flow, International Journal of Heat and Mass Transfer, 56(1-2) (2013) 238-250.

[54] H.M. Soliman, The mist-annular transition during condensation and its influence on the heat transfer mechanism, International Journal of Multiphase Flow, 12(2) (1986) 277-288. 


\section{Figure Captions}

Fig. 1: Basic minigap geometry

Fig. 2: Dependence of heat transfer coefficients on number of hydrophilic areas for specified qualities

Fig. 3: SEM micrograph used for measurement of Teflon $\mathrm{AF}^{\mathrm{TM}}$ coating thickness

Fig. 4 Goniometer images of heat transfer surfaces a) hydrophilic copper surface and b)

hydrophobic Teflon $\mathrm{AF}^{\mathrm{TM}}$ coated surface

Fig. 5: Schematic detailing hydrophobic/hydrophilic patterned surfaces

Fig. 6: Completed hydrophobic/hydrophilic patterned Teflon/copper surfaces

Fig. 7: Test section design

Fig. 8: Detailed test section geometry

Fig. 9: Open loop steam experimental apparatus

Fig. 10: Single-phase comparison of gradient and fluid test section heat transfer rates

Fig. 11: Validation tests using single-phase Nusselt numbers

Fig. 12: Condensation heat transfer coefficients versus average quality for the copper mini-gap

Fig. 13: Comparison of measured copper mini-gap data to predictions with macro-scale Shah

[52] and mini-scale Kim et al. [53] correlations

Fig. 14: Comparison of data from Teflon and copper surfaces

Fig. 15: Comparison of all surfaces at mass flux $\mathrm{G}=150 \mathrm{~kg} / \mathrm{m}^{2} \mathrm{~s}$

Fig. 16 Condensation heat transfer coefficients on hydrophobic/hydrophilic surfaces as compared to copper hydrophilic surface

Fig. 17: Void fraction estimation using Lockhart Martinelli [2] and Homogeneous equilibrium models [5] for mass fluxes of 50 and $200 \mathrm{~kg} / \mathrm{m}^{2} \mathrm{~s}$ 


\section{Figures}

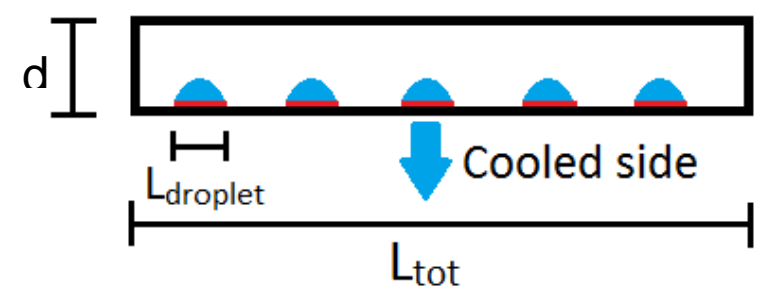

Fig. 1: Basic minigap geometry

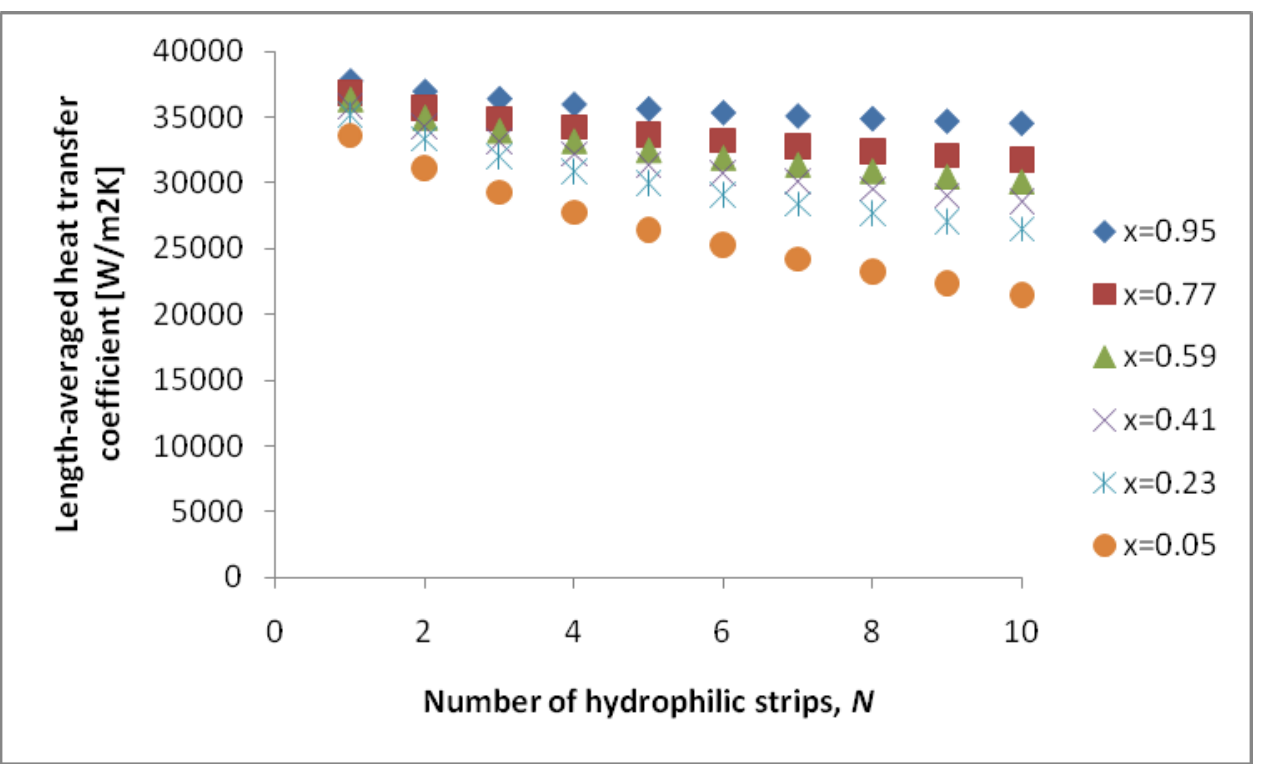

Fig. 2: Dependence of heat transfer coefficients on number of hydrophilic areas for specified qualities 


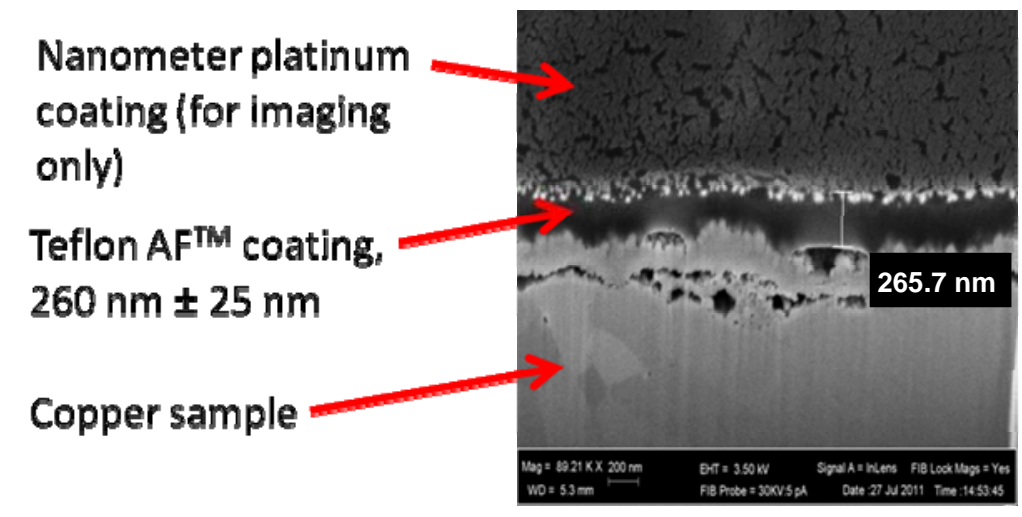

Fig. 3: SEM micrograph used for measurement of Teflon $A F^{T M}$ coating thickness

a)

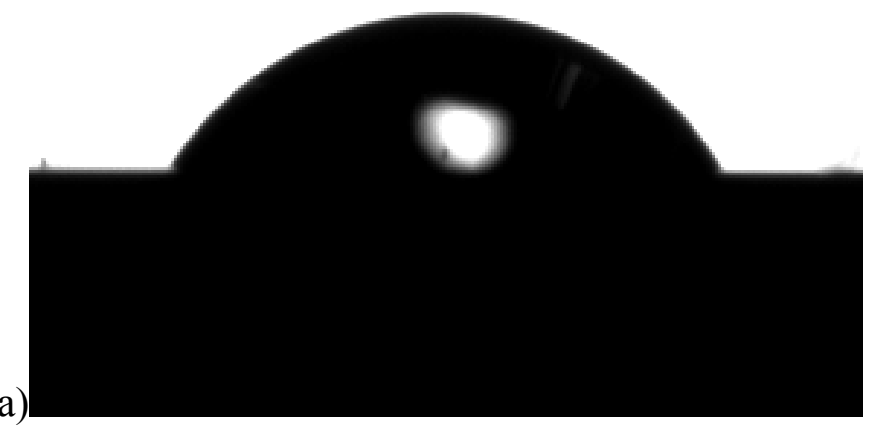

b)

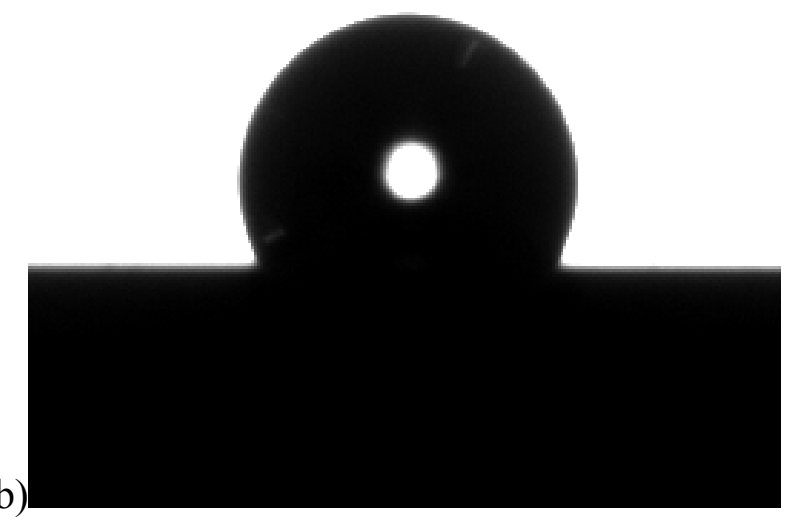

Fig. 4 Goniometer images of heat transfer surfaces a) hydrophilic copper surface and b) hydrophobic Teflon $A F^{T M}$ coated surface 


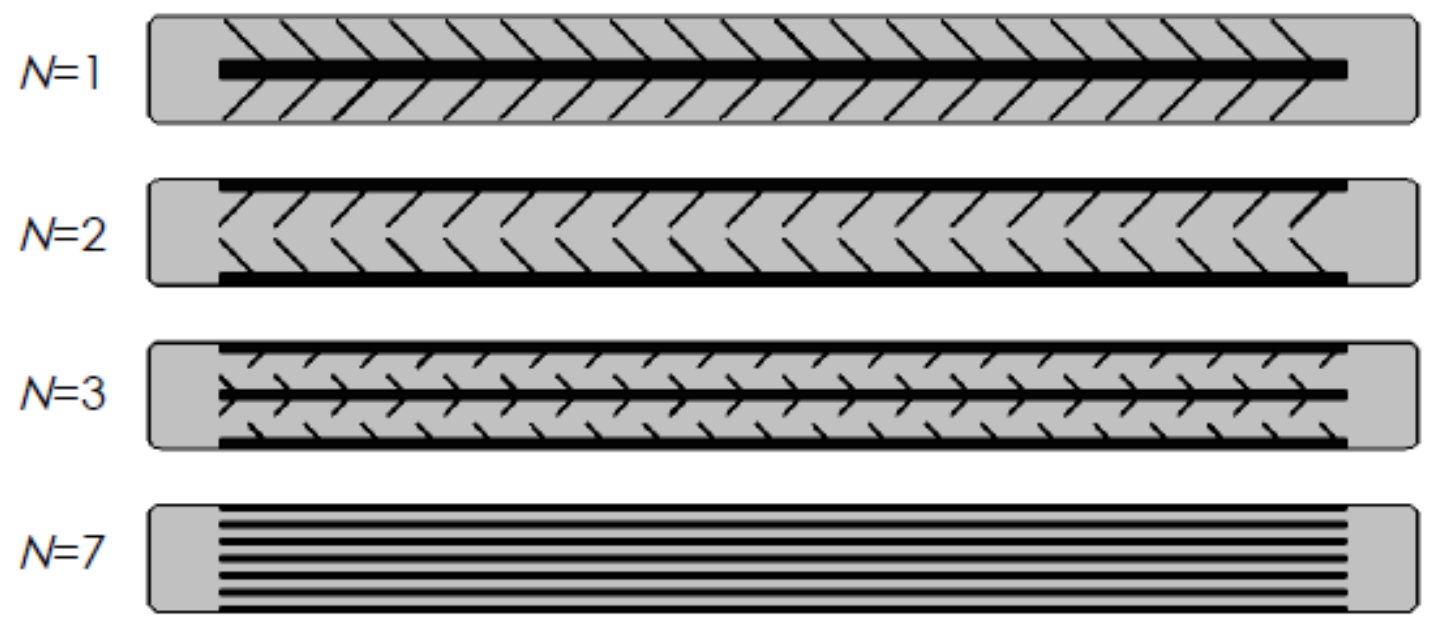

Hydrophobic: gray, hydrophilic: black

Fig. 5: Schematic detailing hydrophobic/hydrophilic patterned surfaces

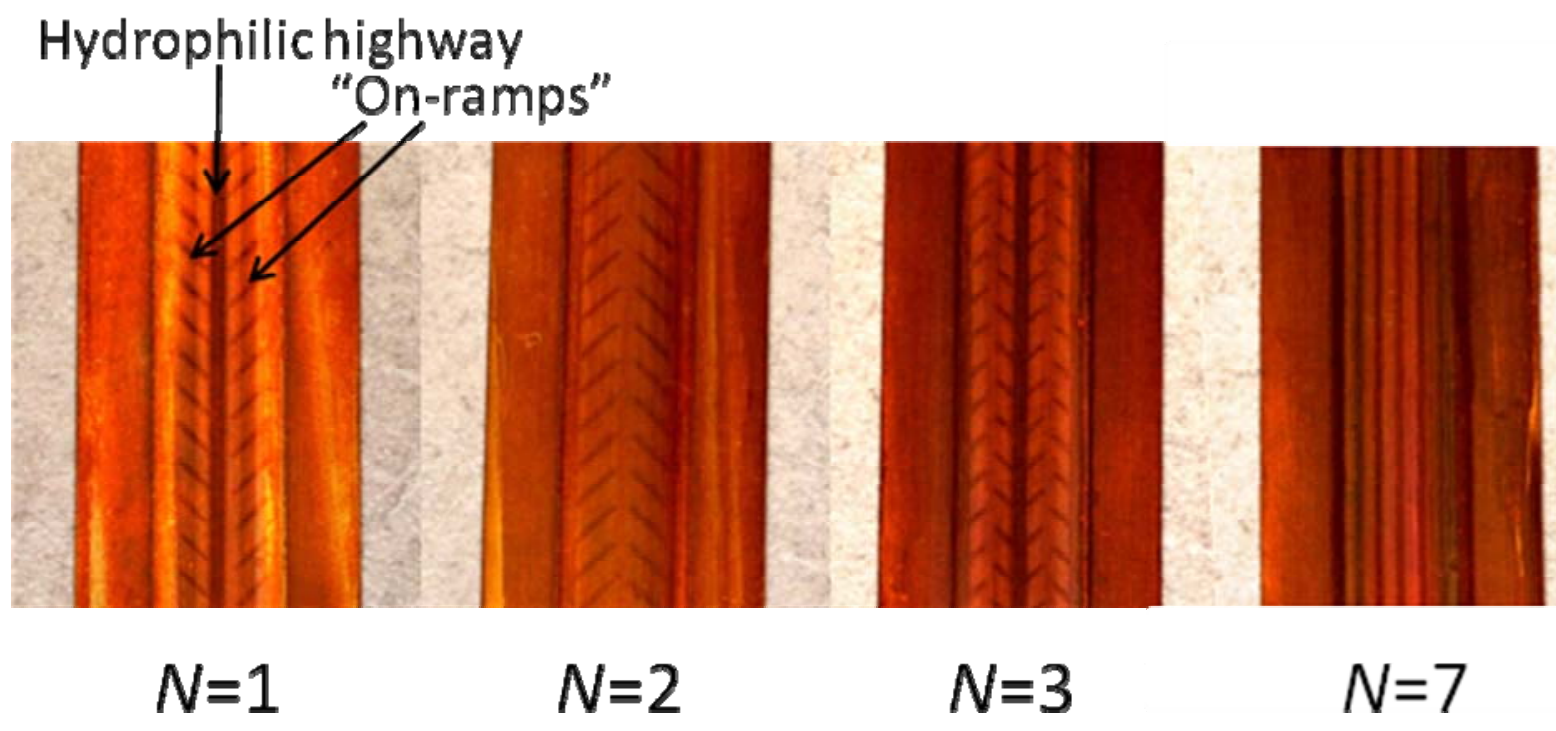

Fig. 6: Completed hydrophobic/hydrophilic patterned Teflon/copper surfaces 


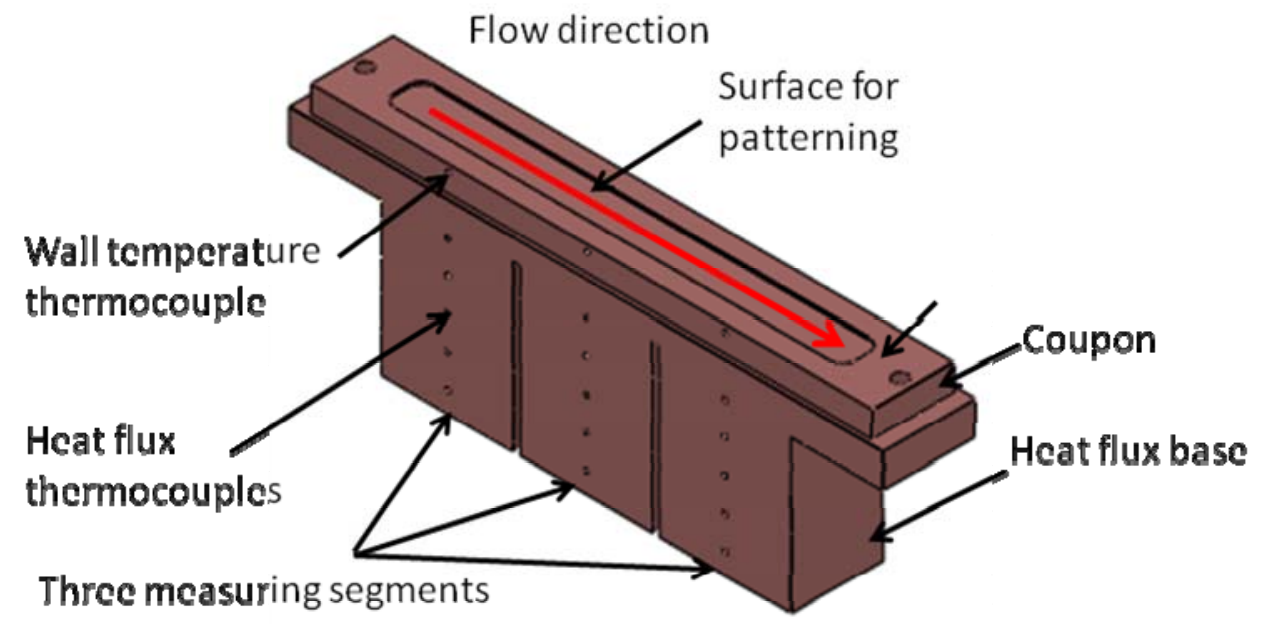

Fig. 7: Test section design

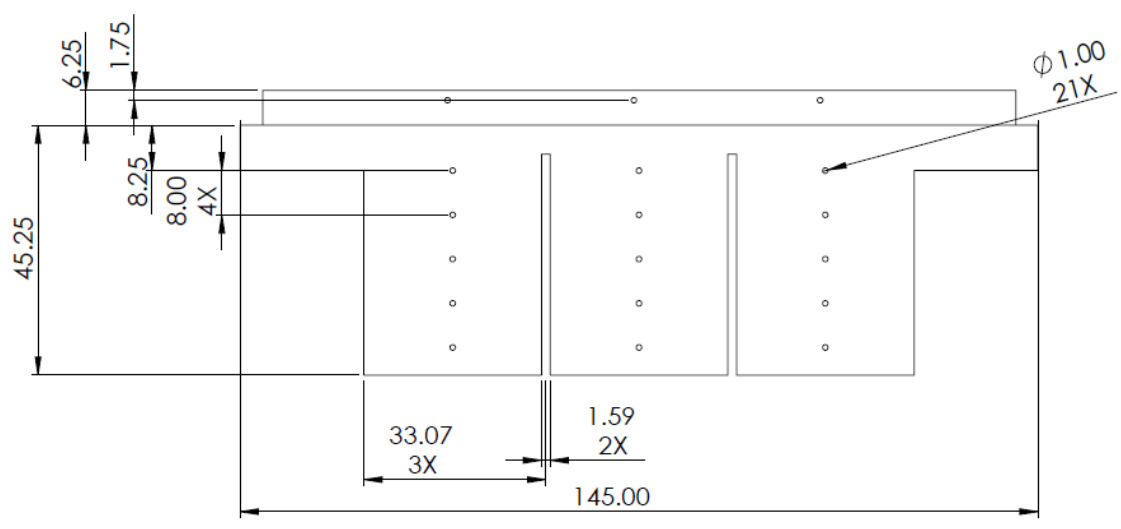

THERMOCOUPLES CENTERED IN MEASURING SEGMENTS ALL DIMENSIONS IN MILLIMETERS

Fig. 8: Detailed test section geometry

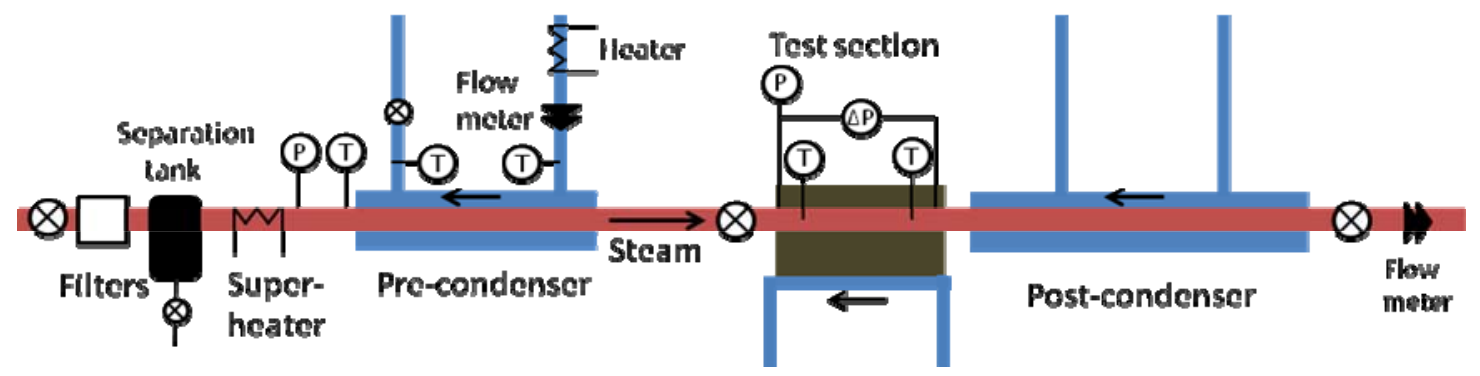

Fig. 9: Open loop steam experimental apparatus 


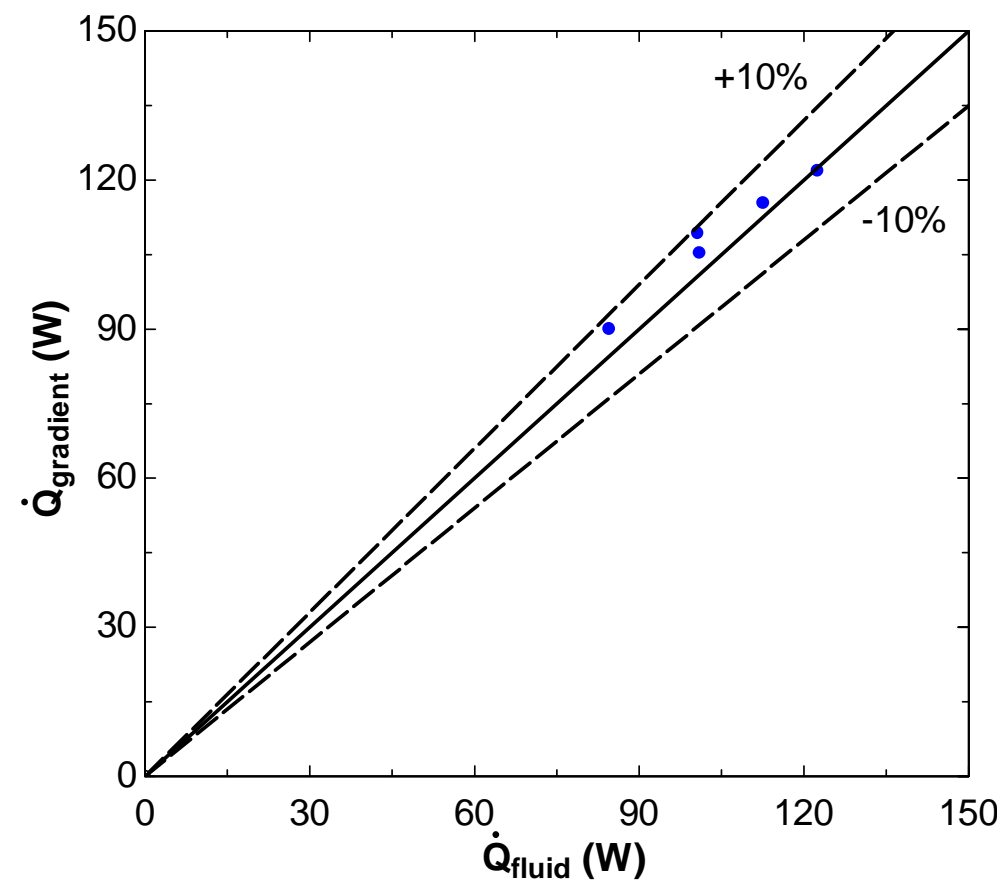

Fig. 10: Single-phase comparison of gradient and fluid test section heat transfer rates 


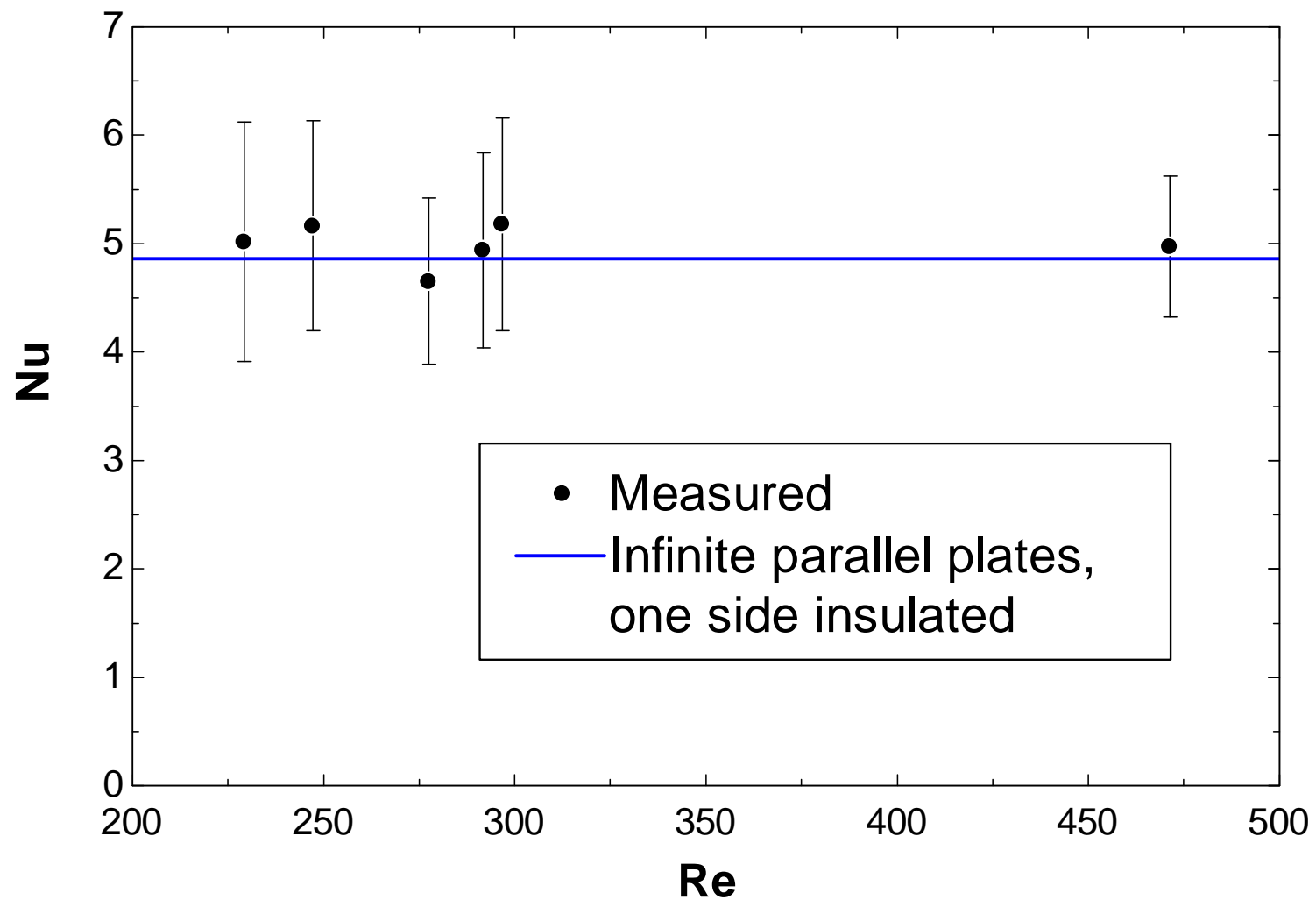

Fig. 11: Validation tests using single-phase Nusselt numbers 


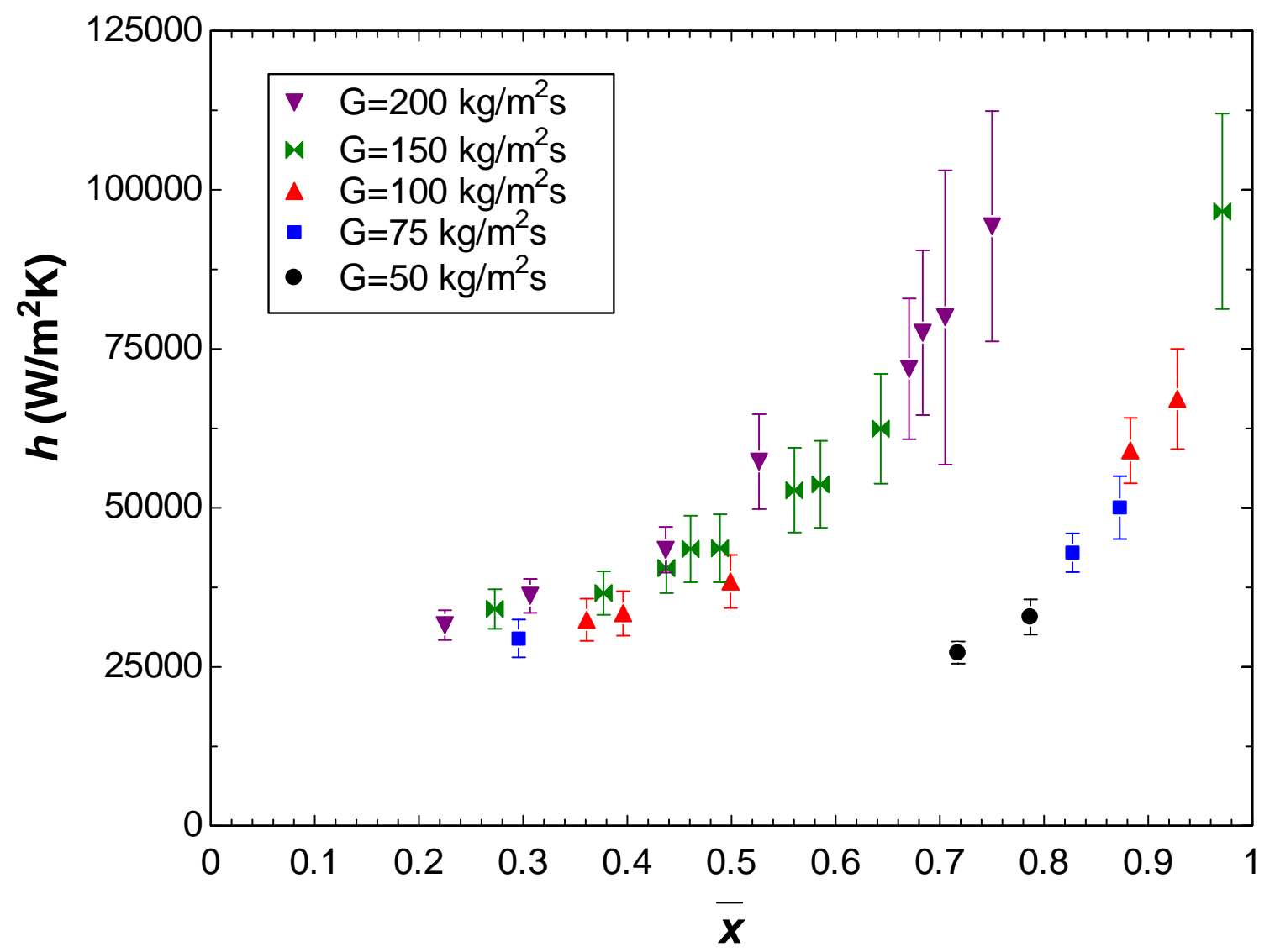

Fig. 12: Condensation heat transfer coefficients versus average quality for the copper minigap 


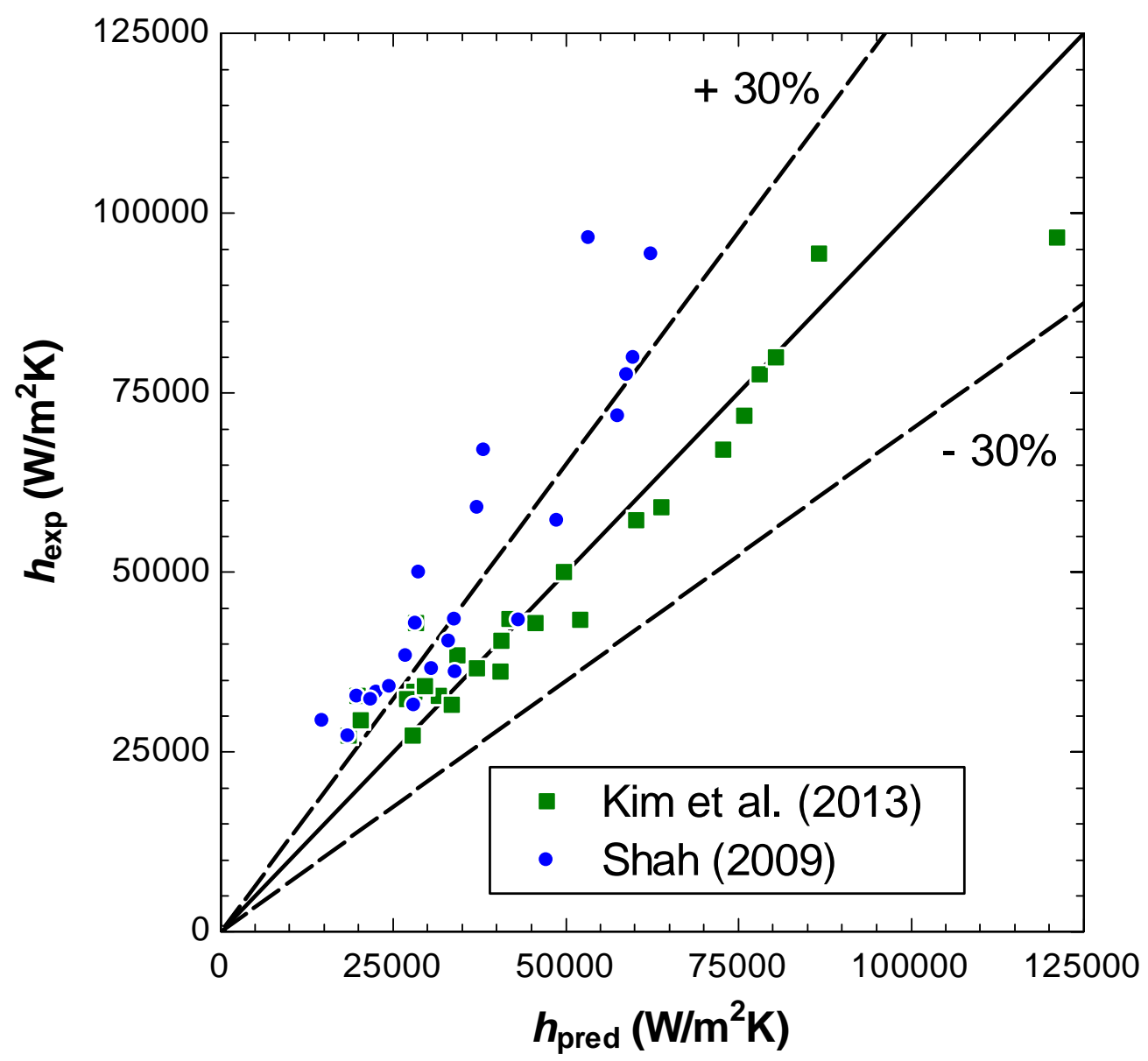

Fig. 13: Comparison of measured copper mini-gap data to predictions with macro-scale Shah [52] and mini-scale Kim et al. [53] correlations 


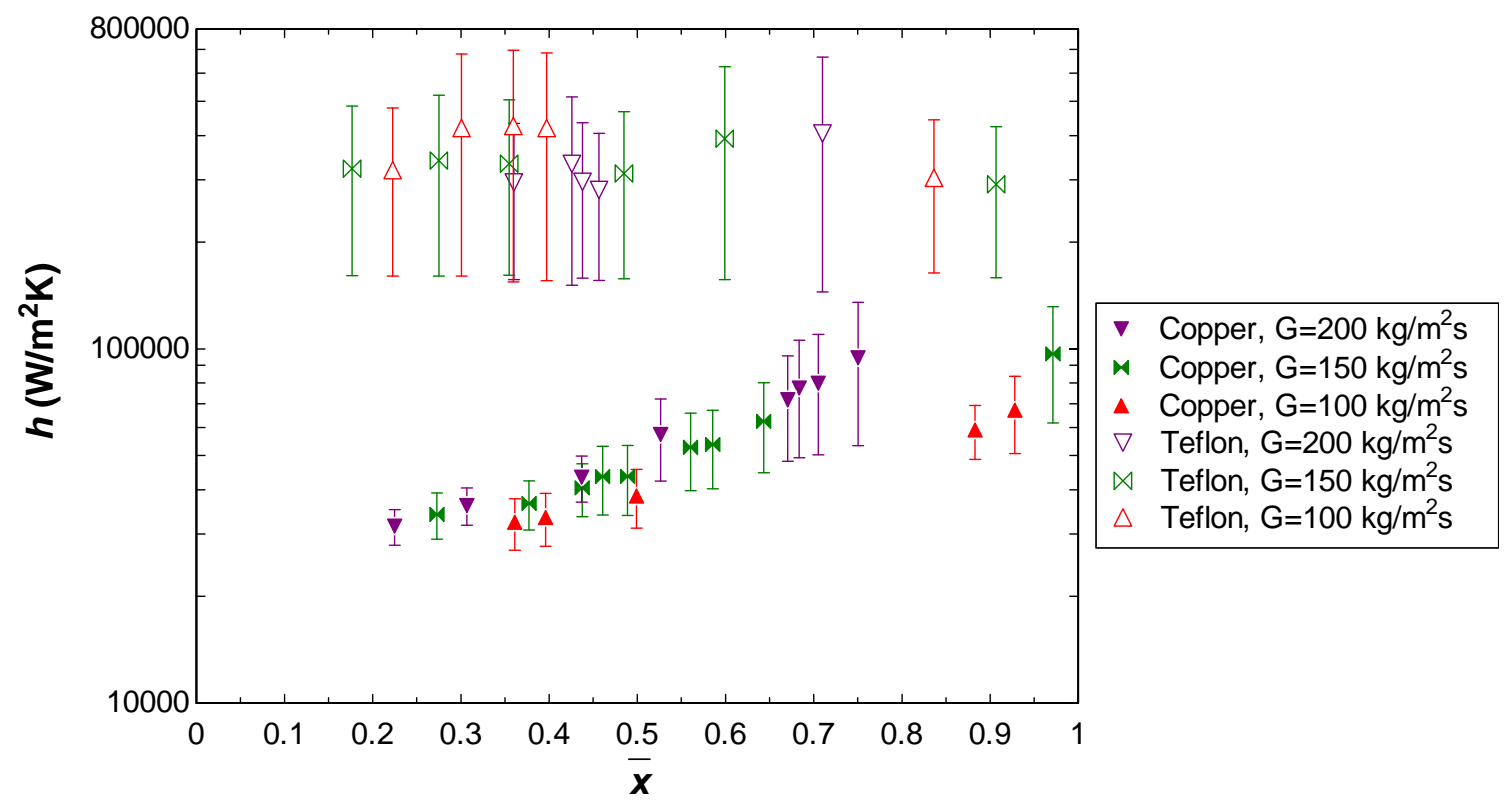

Fig. 14: Comparison of data from Teflon and copper surfaces

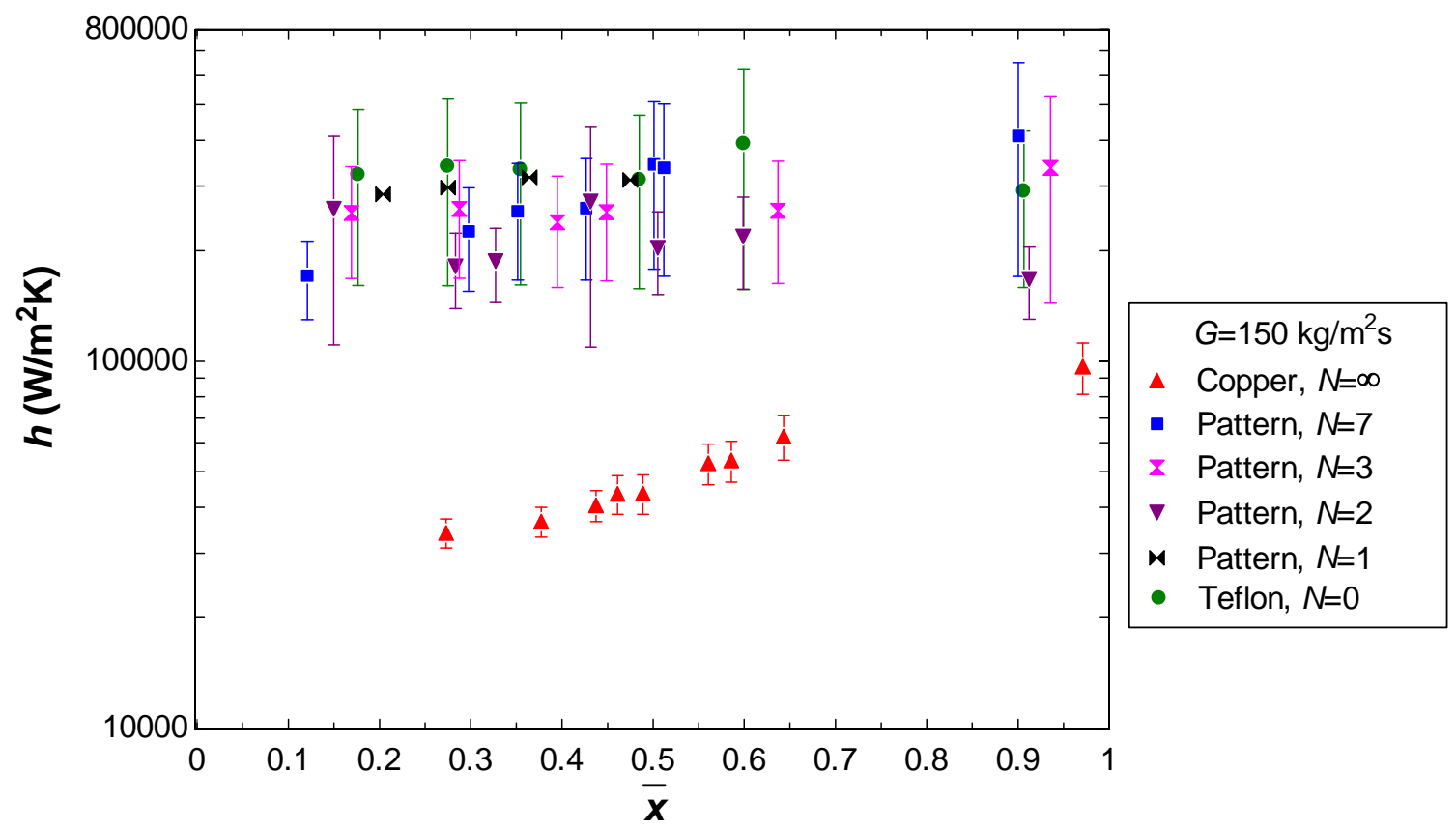

Fig. 15: Comparison of all surfaces at mass flux $G=150 \mathrm{~kg} / \mathrm{m}^{2} \mathrm{~s}$ 


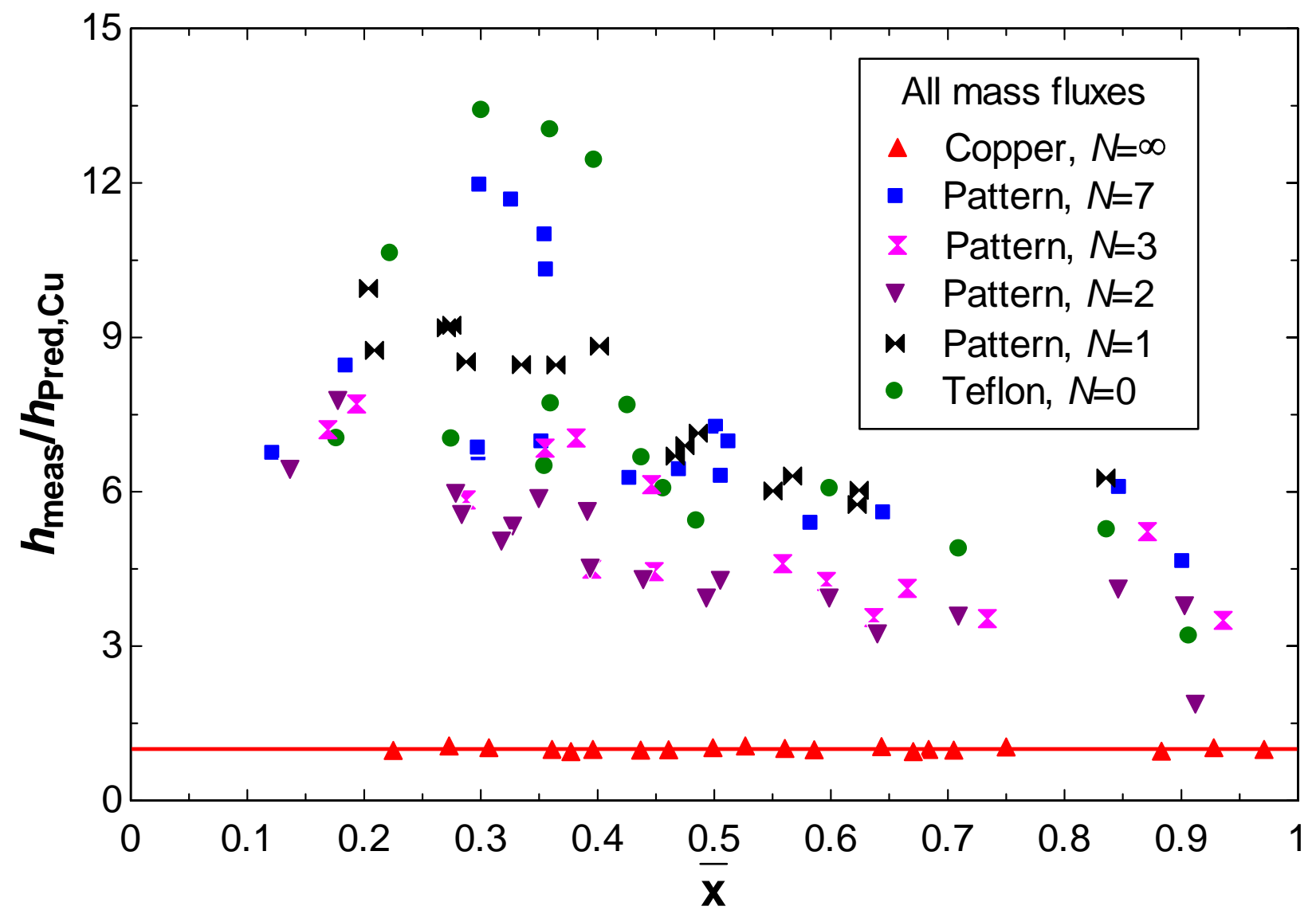

Fig. 16 Condensation heat transfer coefficients on hydrophobic/hydrophilic surfaces as compared to copper hydrophilic surface 


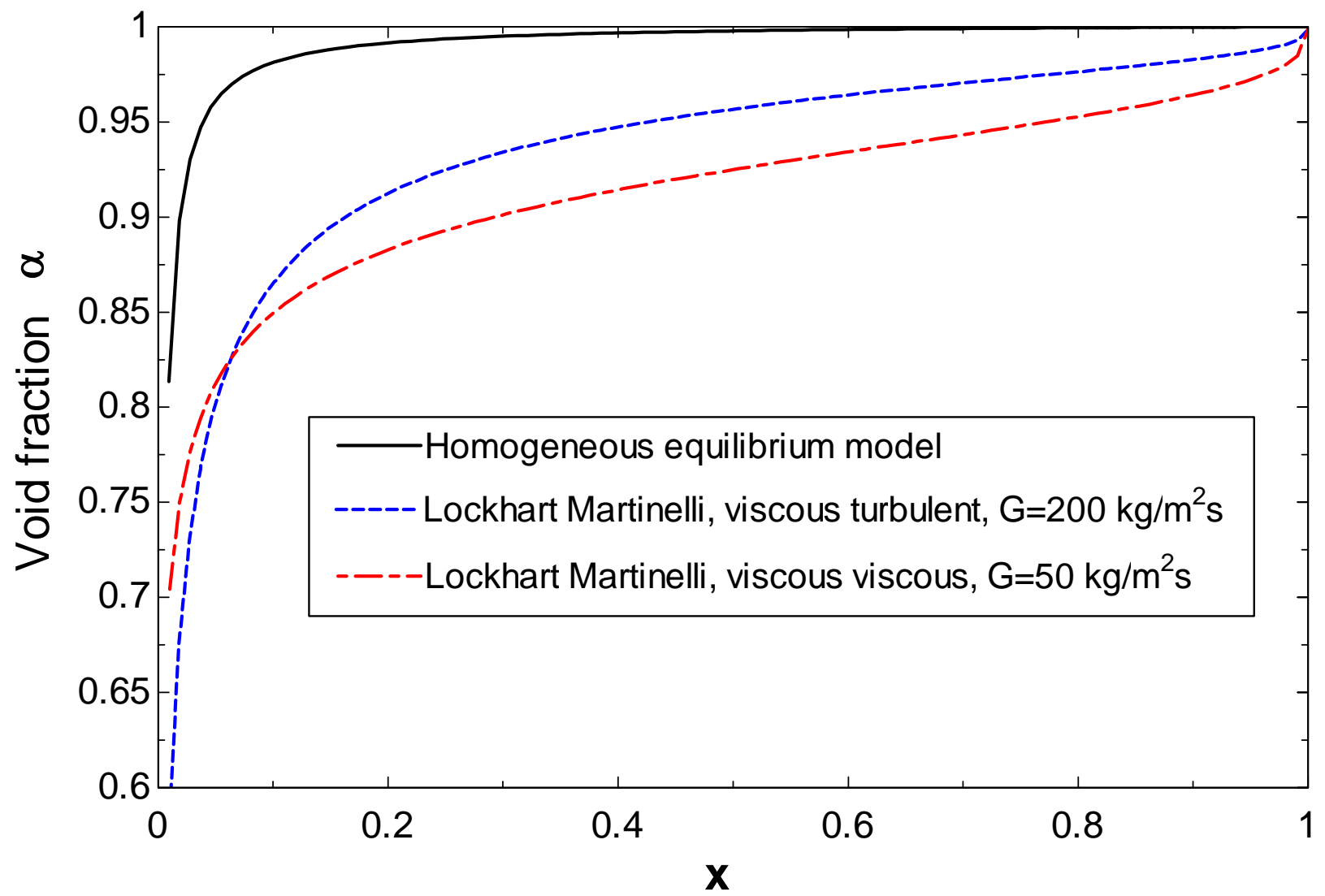

Fig. 17: Void fraction estimation using Lockhart Martinelli [2] and Homogeneous equilibrium models [5] for mass fluxes of 50 and $200 \mathrm{~kg} / \mathrm{m}^{2} \mathrm{~s}$ 


\section{List of Tables}

Table 1: Percent hydrophilic area for different surfaces

\section{Tables}

Table 1: Percent hydrophilic area for different surfaces

\begin{tabular}{|l|c|}
\hline Surface & $\frac{\text { Hydrophtite area }}{\text { Total area }}$ \\
\hline Copper, $N=0$ & $100 \%$ \\
\hline$N=7$ & $33 \%$ \\
\hline$N=3$ & $33 \%$ \\
\hline$N=2$ & $31 \%$ \\
\hline$N=1$ & $13 \%$ \\
\hline Teflon, $N \rightarrow \infty$ & $0 \%$ \\
\hline
\end{tabular}

